\title{
Das Epos als modernerelevante Erzählform
}

Der Begriff des Epischen und die Gattung des Epos verfügen über eine bewegte Geschichte, die in der Antike wurzelt und bis in die Gegenwart hineinreicht. Auch gerade dank dieser langen und gut erforschten Gattungstradition scheint über das Epos seit geraumer Zeit allgemeine Klarheit zu herrschen, Fragen nach dessen ausschlaggebenden formalen und inhaltlichen Merkmalen werden selbst in den neueren Forschungsbeiträgen kaum noch gestellt. ${ }^{1}$ Das Handbuch der Gattungen von 2009 definiert es als „erzählende Versdichtung gehobenen Anspruchs und größeren Umfangs", die aufgrund ihres „oft erhabenen Stils“ „lange Zeit als vornehmste der Gattungen [galt]“. Zum klassischen Epos gehören die „Anrufung der Götter, Musen oder Ahnen“, Teichoskopien sowie Ekphrasis und „wesentliche Gestaltungsmittel in Sprache und Aufbau, [die] aus der Mündlichkeit des öffentlichen Vortrags entstanden“ sind. Der formalen Erhabenheit soll auch inhaltlich entsprochen werden, weshalb epische Stoffe meist der Mythologie, der Götter- und Heldensagen entnommen sind "oder große historische Ereignisse und Persönlichkeiten in den Vordergrund [stellen]", ohne jedoch einen "sich entwickelnden individuellen Charakter dar[zu]stellen."Weiter ziele das Epos

auf die Darstellung weit ausgreifender zeitlicher, geografischer und weltbildlicher Zusammenhänge und strebt danach, die erzählte Welt, [...] in ihrer ganzen Totalität zu erfassen. Dabei zeichnet sich das Epos im Gegensatz zur konzentrierten Intensität des Dramas durch eine panoramatische Extensität, die so genannte epische Breite aus, mittels deren in reihender Episodentechnik, langsamer Entfaltung der Fabel und detailgenauer Ausführlichkeit eine große Ereignisfülle dargestellt wird. In der Regel dominiert zudem eine allwissende, sich kommentierender Wertungen enthaltende Erzählhaltung, die weniger darauf ausgerichtet ist, Spannung zu erzeugen, [...], sondern die vielmehr in ruhiger, distanzierter Betrachtung das Augenmerk auf das Wie des Handlungsgangs lenkt. ${ }^{2}$

1 Vgl. Christians, Heiko: Der Traum vom Epos. Romankritik und politische Poetik in Deutschland (1750-2000). Freiburg i. B.: Rombach 2004. S. 89.

2 Lamping, Dieter (Hrsg.): Handbuch der literarischen Gattungen. Stuttgart: Kröner 2009. S. $204 \mathrm{f}$. 
Dieser Lexikonartikel versammelt in vereinfachter, konzentrierter Fassung sämtliche Bestimmungen, die Hegel kurz nach 1800 in seiner epochemachenden Vorlesung über die Ästhetik festlegt und die gleichwohl schon lange vor Hegel als gängige Gattungsdefinition gelten. Besonders deutlich wird hier die kategorische Auffassung des Epos als der Antike verhaftete, in der Moderne überholte Dichtung: Versform, Götteranrufung und typische anstatt individuelle Figuren stehen im krassen Widerspruch zur neuzeitlichen Lebenswelt und den aus ihr entstehenden Anforderungen an eine zeitgemäße Literatur. Und auch die Merkmale der epischen Breite, der Totalität und Bedächtigkeit werden hier im Kontrast zum Drama als Alleinstellungskriterien definiert, die offensichtlich nicht in Einklang mit den modernen Raum- und Zeitvorstellungen stehen. An diesem Eposverständnis hat sich seit Hegel nicht mehr viel geändert und bis heute wird es von den meisten kulturwissenschaftlichen Disziplinen selbstverständlich und unhinterfragt übernommen. Ist gegenwärtig die Rede vom Epos bzw. vom Epischen, wird einerseits immer noch auf die Urtexte der Gattung referenziert - Homers Odyssee ist nach wie vor Pflichtlektüre im Grundstudium der Germanistik, zumindest stellenweise und andererseits erlebt der Begriff seit der zweiten Dekade des 21. Jahrhunderts eine Renaissance in der Umgangs- und Jugendsprache, ${ }^{3}$ wobei der ursprüngliche Wortgehalt auf "etwas, das sehr lange dauert" oder im Anglizismus epic auf „absolut, überragend, fantastisch“ geschrumpft ist. ${ }^{4}$

Daraus resultiert zunächst die Wahrnehmung, dass das Epische als literarische Gattung tatsächlich seine Produktivität und Relevanz eingebüßt hat; die von Hegel an die moderne Herausbildung der bürgerlichen Gesellschaftsstrukturen geknüpfte Diagnose vom Gattungstod scheint sich zu bestätigen. Bereits ein oberflächlicher Blick in die neuere Gattungsgeschichte macht allerdings sichtbar, dass die Problematisierung und das Bedürfnis nach dem epischen Erzählen immer wieder virulent werden: Bevor die Eposproduktion um die Jahrhundertwende abrupt abbricht, ${ }^{5}$ nimmt sie in der zweiten Hälfte des 19. Jahrhunderts in ganz Europa stark zu, ${ }^{6}$ worauf sich zahl-

3 Vgl. FAZ. http://www.faz.net/aktuell/feuilleton/jugendsprache-krass-war-gestern-es-lebedas-epos-1192786o.html und Spiegel. http://www.spiegel.de/lebenundlernen/schule/ jugendsprache-lass-mal-die-hausaufgaben-guttenbergen-a-801863.html [beide abgerufen am 8.5.2018].

4 http://wortwuchs.net/episch/ [abgerufen am 8.5.2018].

5 Vgl. Michler, Werner: Möglichkeiten einer literarischen Gattungspoetik nach Bourdieu. Mit einer Skizze zur ,modernen Versepik‘. In: Joch, Markus; Wolf, Norbert Christian (Hrsg.): Text und Feld. Bourdieu in der literaturwissenschaftlichen Praxis (= Studien und Texte zur Sozialgeschichte der Literatur, Vol. 108). Tübingen: Niemeyer 2005. S. 189-206, hier S. 203.

6 Vgl. Krauss, Charlotte; Mohnike, Thomas (Hrsg.): Auf der Suche nach dem verlorenen Epos. Ein populäres Genre des 19. Jahrhunderts. Berlin: Lit 2011. S. 7 (Vorwort). 
reiche Autoren und Theoretiker am Beginn des 20. Jahrhunderts dann wieder rückbeziehen werden. ${ }^{7}$ Trotz Hegels Verabschiedung des Epos aus der gegenwärtigen Kunst behält der Begriff des Epischen im ganzen 19. Jahrhundert demnach eine besondere Bedeutung für den deutschen Kulturraum - ein lange vernachlässigtes Forschungsdesiderat, dem die Literaturwissenschaft dank einer kritischen Hinterfragung der hegelschen Epochen- und Gattungskonstrukte nun jüngst Rechnung trägt. ${ }^{8}$ Hier zeigt sich, dass literarische Formen bereits in dieser frühen Phase der Moderne nicht unbedingt an eine Epoche gebunden sind, sondern vielmehr zu verschiedenen Zeitpunkten aufund abtauchen. Ihre Konjunkturen lassen sich also nicht allein aus dem Lauf der Zeit erklären, was die Vorstellung einer linearen, systematischen Gattungsgeschichte grundsätzlich unterläuft und insofern den rigorosen Ausschluss des Epischen aus der modernen Literaturproduktion äußerst verdächtig macht. Diese Einsicht wirft natürlich die Frage auf, welches denn die treibenden Kräfte sind, die zur Reaktualisierung oder Marginalisierung von Gattungen spezifisch dem Epos - führen und verlangt folglich nach einem alternativen Epochen- und Gattungskonzept.

Heinz Brüggemann ${ }^{9}$ und Sabine Schneider ${ }^{10}$ liefern diesbezüglich die neusten, weg-weisenden Ansätze. In Anlehnung an Kosellecks historiographische Konzeption der sich überlagernden Zeitschichten ${ }^{11}$ zeigen sie die Sattelzeit um 1800 von einer grundlegenden Signatur der kulturellen Pluralität gekennzeichnet auf. Es gelingt ihnen nachzuweisen, wie die mit der Aufklärung bewusstwerdende Verfügbarkeit von historischen Zeiten und Stilen den eigentlichen Motor der ästhetischen Moderne ausmacht - einer geschichtlichen Epochenbezeichnung, deren Beschreiben, Definieren und vor allem Datieren grundsätzlich eine unabschließbare Unternehmung ist: Der Begriff

$7 \quad$ Schneider: Erzählen im multiplen Zeitenraum. ,Restitution des Epischen' in der Moderne (Döblin, Benjamin, Musil). S. 215-231.

8 Vgl. Krauss; Mohnike (Hrsg.): Auf der Suche nach dem verlorenen Epos. Ein populäres Genre des 19. Jahrhunderts und Schneider: Erzählen im multiplen Zeitenraum. ,Restitution des Epischen' in der Moderne (Döblin, Benjamin, Musil). S. 215-231.

9 Brüggemann, Heinz: Modernität im Widerstreit. Zwischen Pluralismus und Homogenität. Eine Theorie-, Kultur- und Literaturgeschichte (18.-20. Jahrhundert). Würzburg: Königshausen \& Neumann 2015.

10 Schneider, Sabine: Klassizismus und Romantik - zwei Konfigurationen der einen ästhetischen Moderne. Konzeptuelle Überlegungen und neuere Forschungsperspektiven. In:Jahrbuch der Jean Paul Gesellschaft 37 (2002). S. 86-128. Gemeinsam mit Brüggemann, Heinz: Gleichzeitigkeit des Ungleichzeitigen. Formen und Funktionen von Pluralität in der ästhetischen Moderne.

11 Vgl. Koselleck, Reinhart; Gadamer, Hans-Georg (Hrsg.): Zeitschichten. Studien zur Historik. Frankfurt a. M.: Suhrkamp 200o. S. 19-26. 
der Moderne zielt stets auf das Neue, Aktuelle und Zukunftsgerichtete; er wird immer dann virulent, wenn sich das politische und kulturelle Selbstverständnis einer Gesellschaft gravierend verändert und sich deutlich von demjenigen der Vorgänger absetzt. ${ }^{12}$ Für die neuere europäische Kulturgeschichte kann deshalb der Streit zwischen "den Alten und den Modernen“"13, der gegen Ende des 17. Jahrhunderts die Aufklärung initiiert, als Beginn einer Moderne verstanden werden, die sich bis in die Gegenwart immer wieder selbst überholt.. ${ }^{14}$ Deren ausschlaggebende Parameter sind gemäß Jürgen Osterhammel der

Beginn eines langfristigen Wachstums der Pro-Kopf-Einkommen; eine rationale, rechenhafte Lebensführung; der Übergang von der Stände- zur Klassengesellschaft; die Ausweitung politischer Partizipation; die Verrechtlichung von Herrschaftsverhältnissen und gesellschaftlichem Umgang; die Entwicklung von Zerstörungskapazitäten neuartiger Dimension; die Umorientierung der Künste von der Nachahmung der Tradition zur kreativen Zerstörung ästhetischer Normen. ${ }^{15}$

Vgl. Müller, Klaus Peter: Moderne. In: Nünning, Ansgar (Hrsg.): Metzler Lexikon Literaturund Kulturgeschichte. Ansätze - Personen - Grundbegriffe (vierte, aktualisierte und erweiterte Auflage). Stuttgart: Metzler 2008. S. 508-511, hier S. 508. Moderne als Begriff des Wandels, des Umbruchs und der Erneuerung lässt sich folglich auf diverse Gegenstandsbereiche beziehen, davon zeugen auch die zahlreichen Moderne-Variationen wie literarische, ästhetische, politische, kulturelle, technische etc. Moderne, mit ihren jeweils eigenen Datierungs- und Beschreibungsdiskursen. Daraus ergeben sich zeitliche, örtliche und programmatische Überschneidung sowie Diskrepanzen, die Koselleck und Andere als Gleichzeitigkeit des Ungleichzeitigen beschreiben. Gemäss Koselleck überlagern sich jedoch um 1800 Modernisierungsschübe in Gesellschaft, Politik und Kunst, die sich gerade mit diesem Problem zeitlicher Heterogenität auseinandersetzen und in dieser Verdichtung einen umfassenden, epochalen Wandel - sprich eine Epochenschwelle ausprägen, deren ausschlaggebendes, die Gegenstandbereiche verbindendes Merkmal die Bewusstwerdung einer neuen Zeit ist, vgl. Koselleck, Reinhart: Das achtzehnte Jahrhundert als Beginn der Neuzeit. In: Ders.; Herzog (Hrsg.): Epochenschwelle und Epochenbewusstsein. S. 269-282, hier S. 278. In Bezug auf die Entwicklungsgeschichte literarischer Gattungskategorien misst auch Michler der Ausprägung einer sogenannten Sattelzeit um 18 oo als Verhandlungsort modernen Wissens größte Bedeutung bei, vgl. Michler, Werner: Kulturen der Gattung. Poetik im Kontext 1750-195o. Göttingen: Wallstein 2015. S. 13.

13 Die epochemachenden Querelles des Anciens et des Modernes werden von Charles Perrault 1687 in der französischen Akademie ausgelöst, darin gewinnt die Moderne die Überhand gegenüber der Tradition der Antike und der Vergangenheit schlechthin, vgl. Müller: Moderne. S. 508-511, hier S. 508.

14 Vgl. Koselleck, Reinhart; Bergeron, Louis et al.: Das Zeitalter der europäischen Revolution: 1780-1848. Frankfurt a. M.: Fischer Bücherei 1969 (= Fischer Weltgeschichte, Bd. 26). S. 303 .

15 Osterhammel, Jürgen (Hrsg.): Die Verwandlung der Welt. Eine Geschichte des 19. Jahrhunderts (= Historische Bibliothek der Gerda Henkel Stiftung). München: Beck 2009. S. 1282 . 
Von Anfang an stellen sich also die Steigerung von Selbstbewusstsein und Selbstbezug sowie eine allgemeine Fortschrittsdynamik als die ausschlaggebenden und sich durchsetzenden Charakteristiken der Moderne heraus. Wie Sabine Schneider jedoch geltend macht, beginnen die aufklärerischen Konzepte der zunehmend auf das Subjekt bezogenen Selbstbewusstwerdung bereits in der Sattelzeit um 1800 problematisch zu werden und die eigenen Voraussetzungen gerade reflexiv zu hintertreiben. ${ }^{16}$ Der Begriff der Moderne ist demnach schon zu diesem frühen Zeitpunkt kein historischer mehr, sondern vielmehr ein moralisch-psychologischer, der sich je nach Perspektive mit unterschiedlichen Wertungen fassen und gegen andere Konzepte in Stellung bringen lässt.

In eben diesen Kontext stellt Willems bezeichnenderweise auch die am Ende des 18. Jahrhunderts allgegenwärtige Rede von Klassizität, ${ }^{17}$ die immer

16 Vgl. Schneider: Klassizismus und Romantik - zwei Konfigurationen der einen ästhetischen Moderne. Konzeptuelle Überlegungen und neuere Forschungsperspektiven. S. 89 .

17 Zu den Begriffen der Klassik und des Klassizismus: Der Begriff des ,Klassizismus d definiert sich über die Referenz auf die Kunst und Architektur der griech.-röm. Antike, während der Begriff der Moderne gerade das Nicht-Antike, das Gegenwärtige bezeichnet. Das Klassische bezeichnet etymologisch immer etwas Besonderes, Musterhaftes, Vorbildliches. Darin liegen die wertende und normative Komponente, die Anlage zu Kanonisierungs- und Ausgrenzungsfunktionen des Begriffs, die sich auch die Propagandisten der ,Deutschen Klassik' bewusst zunutze machen. Klassische Zeitalter sind deshalb immer historisch verankert, das Prädikat des Klassischen hängt davon ab, was zu einem bestimmten Zeitpunkt als vorbildlich-herausragend angesehen wird, deshalb wird es stets in der Retrospektive verliehen. Das gilt auch im Fall der historischen, alle Künste erfassenden gesamteuropäischen Diskursformationen des 18. Jahrhunderts, die sich durch einen vielseitigen Antikenbezug einerseits und andererseits einen prononcierten Versuch, den eigenen Stil vom vorhergehenden abzugrenzen, auszeichnen, vgl. Glaser, Hermann; Lehmann, Jakob et al. (Hrsg.): Wege der deutschen Literatur. Eine geschichtliche Darstellung. Berlin: Ullstein 1997. S. 175 und Schweikle, Günther; Zabka, Thomas: Klassik. In: Burdorf, Dieter; Fasbender, Christoph et al. (Hrsg.): Metzler Lexikon Literatur. Begriffe und Definitionen (dritte, völlig neu bearbeitete Auflage). Stuttgart: Metzler 2007. S. 385 . Die Akteure des sogenannten dt. Klassizismus haben sich selbst nie das Prädikat des Klassischen verliehen, vgl. Vosskamp, Wilhelm (Hrsg.): Klassik im Vergleich. Normativität und Historizität europäischer Klassiken (DFG-Symposium 199o). Stuttgart: Metzler 1993. S. 6. Erst im Laufe des 19. Jahrhunderts wird aus dieser geistigen Bewegung eine Epochenbezeichnung, die eine normativ vorbildliche dt. Klassik mit innerer Wesensverwandtschaft mit der griech. Klassik postuliert. Über den genauen Zeitrahmen der Dt. Klassik ist sich dann die Literaturgeschichte auch nicht einig, die normativen Zugriffe bezeichnen die unterschiedlichsten Zeiträume zwischen 1775 und $183^{2}$ als dt. Klassik. Um dem Vorwurf der Beliebigkeit zu entgehen, wird die dt. Klassik oft mit der Weimarer Klassik gleichgesetzt, vgl. ebd. S. 9 und Schlosser, Horst Dieter (Hrsg.): dtv-Atlas Deutsche Literatur. München: dtv 1999. S. 163. Die Weimarer Klassik bezeichnet jedoch eine örtlich, zeitlich und personell sehr eng gefasste, klassizistische Phase: Gemeint ist die Zeit von 1786 bis 1805, als Goethe und Schiller sich beide in Weimar aufhalten und untereinander sowie mit Herder und Wieland einen regen Gedankenaustausch pflegen. Mit diesem engen Rahmen 
noch auf die Vorstellung eines "goldenen Zeitalters" referenziert. Deren Basis die gesicherte, sich auf einen antiken Musterkanon beziehende „Fundierung der Literatur in Normen“18 - ist jedoch bereits brüchig geworden. Davon ausgehend weist er in seinem Aufsatz, in dem er Goethe als „klassischen deutschen Nationalautor" kanonisiert, die sogenannte Deutsche Klassik aufschlussreich als ein „spekulatives, höchst fragwürdiges literaturhistorisches Konstrukt“ aus, dessen Konstituierung mit Herders poetologischer Idealisierung Goethes anfängt und in der Kunsttheorie der Romantik schließlich politischnationalistisch konsolidiert wird. ${ }^{19}$ Ist im Weiteren also die Rede vom Klassizismus oder der Klassik, ist damit Willems folgend die geistige und ästhetische Strömung der Epochenschwelle um 1800 gemeint, deren intensivierte Auseinandersetzung mit der Antike einer Endphase der sich durch das ganze 18. Jahrhundert hindurchziehenden Querelles gleichkommt. Den eigentümlichen Charakter dieser Zeit, in der die Moderne - sprich die moderne, romantische Literatur - nun die antiken Muster und Kunstauffassungen endgültig ablöst, macht gerade das Kritisieren der Mimesis-Programme zum einen und das gleichzeitige Festhalten an der griechischen Dichtung als normativem Vorbild zum anderen aus. $^{20}$ Erwartungsgemäß werden die ästhetischen

werden aber Beiträge zu klassizistischen Konzepten von anderen Akteuren, die jenseits davon entstehen, wiederum ausgeschlossen. Es ist gerade deshalb auch ein zentrales Ziel dieser Arbeit aufzuzeigen, wie problematisch eine derart rigide Epochenteilung ist und sie wird versuchen, die epochenübergreifenden Gemeinsamkeiten, Zusammenhänge und Reibungspunkte zwischen Sturm-und-Drang, Klassik, Romantik, Aufklärung und Französischer Revolution innerhalb der ausgewählten Literatur hervorzuheben. Zur Problematik der Klassik als Literaturepoche vgl. Conrady, Karl Otto: Anmerkungen zum Konzept der Klassik. In: Ders.; Albertsen, Leif Ludwig (Hrsg.): Deutsche Literatur zur Zeit der Klassik. Stuttgart: Reclam 1977. S. 7-29 sowie Vosskamp (Hrsg.): Klassik im Vergleich. Normativität und Historizität europäischer Klassiken (DFG-Symposium 1990). Darin insb. ders.: Einführung. S. 9-11 und Werner, Hans-Georg: Über den Terminus „Klassische deutsche Literatur“. S. 12-24. Weiter auch Vosskamp: Klassik als Epoche. Zur Typologie und Funktion der Weimarer Klassik. S. 493-514.; ders.: Europäische Literatur und nationalgeschichtliche Funktion - eine Replik auf H. R. Jauss. In: Herzog; Koselleck (Hrsg.): Epochenschwelle und Epochenbewusstsein. S. 587-589 und Koselleck, Reinhart: Das achtzehnte Jahrhundert als Beginn der Neuzeit. In: Ebd. S. 269-282. Spezifisch zur Weimarer Klassik vgl. auch Borchmeyer, Dieter: Die Weimarer Klassik. Eine Einführung, Bd.1. Königstein: Athenäum 1980.

18 Willems: „Ihr habt jetzt eigentlich keine Norm, die müsst ihr euch selbst geben“. Zur Geschichte der Kanonisierung Goethes als „klassischer deutscher Nationalautor“. S. 103134, hier S. 104.

19 Ebd.

20 Ebd. S. 111. Auch Koselleck und Vosskamp stellen das Projekt einer deutschen Klassik (bzw. spricht Vosskamp von der Weimarer Klassik) in Zusammenhang mit der grundlegenden Krisenerfahrung der Neuzeit, was nicht nur als Folge, sondern gerade auch als 
und literaturtheoretischen Konzepte, die unter derartigen Bedingungen erscheinen, aber kaum eine Einheit bilden, sondern viel eher von inhärenten Widersprüchen geprägt sein.

Im Zuge davon erscheinen Klassizismus und Romantik nicht länger als klar definierte und voneinander getrennte Kunstepochen in einem linearen Abfolgeverhältnis, ${ }^{21}$ sondern - mit Blick auf Kosellecks Theorem von der Gleichzeitigkeit des Ungleichzeitigen - als doppelte, komplementäre Ursprünglichkeit einer ästhetischen Moderne, die nicht ausschließlich durch das Prinzip der Fortschrittslogik bestimmt ist. Diese veränderten Prämissen der Epochenwahrnehmung - dass Aufklärung, Klassizismus und Romantik als unterschiedliche, aber gleichzeitig wirksame ästhetische Programme erscheinen, als vielstimmiger „Prozess der einen ästhetischen Moderne ${ }^{“ 22}$ verpflichten auch zu einer Revision der konventionellen ästhetischen und programmatischen Zuschreibungen. So weist zum Beispiel der vom Zentrum für Klassikforschung herausgegebene Sammelband Heikle Balancen die Weimarer Klassik als differenzierten Reflexionsort des zeitgenössischen gesellschaftlichen und wissenschaftlichen Paradigmenwechsels aus. Die steten Bemühungen um einen Ausgleich zwischen den sich akzentuierenden Gegensätzen werden darin als fragile Versuchsanordnungen aufgezeigt, die ein sensibles und kritisches Bewusstsein für die angebrochene Moderne beweisen. ${ }^{23}$ Dem Klassizismus, als spezifischer Diskursform in einem dialogischen Verhältnis zur Romantik, wird dadurch zugestanden, einen genuinen Beitrag zur frühen Moderne zu leisten. So wird die vermeintlich programmatische Unvereinbarkeit von Klassizismus und Moderne ein Stück weit widerlegt.

Wie bereits angedeutet, hat die Aufhebung der konventionellen Epochenteilung auch Konsequenzen für das traditionelle Gattungssystem - die Auffassung, dass literarische Formen in einem historisch verfassten, unaufhaltsam

Antwort auf die Pluralisierungs- und Beschleunigungserfahrung gelesen werden kann, vgl. Vosskamp: Klassik als Epoche. Zur Typologie und Funktion der Weimarer Klassik. S. 493-514, hier S. 494.

21 Wie das z.B. Fitz Strichs Monographie mit nachhaltiger Wirkung aufgebaut hat, vgl. Strich, Fritz: Deutsche Klassik und Romantik, oder Vollendung und Unendlichkeit: Ein Vergleich. Bern: Francke 1962. Dazu, inwiefern dies lange als gefestigte Tatsache der Literaturgeschichte galt, vgl. Vosskamp: Klassik als Epoche. Zur Typologie und Funktion der Weimarer Klassik. S. 493-514 hier S. 493.

22 Brüggemann, Heinz (Hrsg.): Romantik und Moderne. Moden des Zeitalters und buntscheckige Schreibart. Aufsätze. Würzburg: Königshausen \& Neumann 2009.

23 Vgl. Valk, Thorsten (Hrsg.): Heikle Balancen. Die Weimarer Klassik im Prozess der Moderne (= Schriftenreihe des Zentrums für Klassikforschung, 1). Göttingen: Wallstein 2014. 
vorwärtsschreitenden Ablöseverhältnis der Traditionen stehen, kann gegen die so überzeugend ins Feld getragenen Erkenntnisse über die epochemachenden Prinzipien von Pluralität, Gleichzeitigkeit und Gemengelage nicht länger aufrechterhalten werden.

Auch hier braucht es neue verfeinerte, alternative Zugriffe auf und Konzepte für die Formen der Literatur, ihre Mutationen und Konjunkturen. Die Kategorie der Gattung drohte aufgrund derartig theoretischer und konzeptueller Erosion zwischenzeitlich fast vollständig aus der Literaturwissenschaft zu verschwinden, ${ }^{24}$ in den neueren Debatten erlebt sie aber dank innovativer Differenzierung des Gattungsbegriffs eine Renaissance. Für das hier verfolgte Forschungsinteresse erweisen sich besonders die Verbindungen mit den Ansätzen der Wissensgeschichte ${ }^{25}$ und speziell der Wissenspoetologie ${ }^{26}$ als höchst produktiv: Ausgehend von der Prämisse, dass literarische Form und Wissen in einem konstitutiven Zusammenhang stehen - nämlich, dass Wissen stets einer Inszenierung bedarf, um überhaupt verfügbar zu werden und dass diese ein eigenes Wissen besitzt - werden Entstehung, Entwicklung und Funktionalität von Gattungen aus einer epistemologischen Perspektive neu beleuchtet. Als distinkte Formen der Darstellung bzw. Inszenierung wird Gattungen somit ein eigenes, literarisches Wissen zugestanden, das sich vom Wissen anderer Wissenssysteme unterscheidet. Zu welchen Einsichten poetische Texte führen, welches spezifische Wissen ihnen eigen ist und wie Gattungen zur Konstitution und Organisation dieses Wissens beitragen, sind die erkenntnisleitenden Interessen einer neuen, alternativen Gattungspoetik. Sie rückt gattungsspezifische Repräsentationsweisen als Verfahren in den Fokus, die das „Auftauchen neuer Wissensobjekte und Erkenntnisbereiche zugleich als Form ihrer Inszenierung ${ }^{\prime 27}$ begreifbar machen. So lässt sich aufzeigen, dass Gattungskonzepte signifikanten Anteil haben an der Tradierung, Konsolidierung und Legitimierung von Inhalten, Wahrnehmung und Deutungen, dass sie in poetischer Verdichtung auf Veränderungsprozesse, neue Denkmodelle und Episteme reagieren sowie an deren Modifikation und Reflexion teilhaben. Sie überliefern und transformieren kulturelles Wissen und

\footnotetext{
24 Vgl. Michler: Kulturen der Gattung. Poetik im Kontext 1750-1950. S. 10.

25 Vgl. Bies, Michael; Gamper, Michael et al. (Hrsg.): Gattungs-Wissen: Wissenspoetologie und literarische Form. Göttingen: Wallstein 2013 und Berg, Gunhild (Hrsg.): Wissenstexturen. Literarische Gattungen als Organisationsformen von Wissen (= Berliner Beiträge zur Wissens- und Wissenschaftsgeschichte, Bd. 17). Frankfurt a. M.: Peter Lang 2014.

26 Vgl. Vogl, Joseph: Poetologien des Wissens um 180o. München: Fink 1999.

27 Ebd. S. 12.
} 
sind gleichzeitig selbst offen für Transformationen und Neubesetzungen. ${ }^{28}$ Literarische Formen werden so nicht länger als in einem unhintergehbaren Abfolgeverhältnis verhaftet beschrieben, sondern als dynamische, veränderliche Kategorien mit unterschiedlichen Funktionen, die gleichzeitig existieren, sich komplementieren, konkurrieren oder sich sogar vermischen.

Ein derart pluralistisches Gattungsverständnis kann das Verhältnis der beiden Erzählformen Epos und Roman an der Epochenschwelle ${ }^{29}$ als koexistierende Varianten des Epischen beleuchten, denen jeweils unterschiedliche, modernespezifische Funktionen und Qualitäten zugeschrieben werden und die in einem beweglichen, spannungsvollen und zuweilen sogar prekären Verhältnis zueinander stehen. Diesbezüglich soll hier pointiert auf die Forschungen von Helmut J. Schneider und Werner Michler verwiesen werden, die die gattungsinternen Ausdifferenzierungen gezielt mit den zeitgenössischen soziopolitischen Verschiebungen in Beziehung setzen und dadurch die besondere Bedeutung des Epos für die komplexen Wechselwirkungen zwischen ästhetischem Formdenken, Gattungswahl und sozialer Klassifikation sichtbar machen. ${ }^{30}$ Wie Michler in seiner Anwendung von Bourdieus Feldtheorie auf Fragen der Gattungspoetik einleuchtend aufzeigt, bestehen große systemische Affinitäten und Wechselwirkungen zwischen literarischen Gattungen und sozialen Strukturen: Beide generieren stabile Regeln, klassifizierbare und praktikable Produktionsformen; sie bringen zugleich die Unterscheidungs- und Bewertungskriterien hervor, um über Einhaltung oder Abweichung dieser Formen und das Gelingen ihrer Produkte zu entscheiden. Dadurch vermögen sie eine grundlegende Vermittlung zwischen dem Individuellen bzw. dem Einzelwerk und dem Kollektiven bzw. der Literatur zu leisten. ${ }^{31}$ Es darf deshalb auch nicht erstaunen, wie überzeugend es Michler gelingt, einen konstitutiven Zusammenhang zwischen der Intensivierung von Gattungsdiskussionen und sozialen sowie literaturästhetischen

28 Vgl. Schneider, Sabine; Drath, Marie (Hrsg.): Prekäre Idyllen in der Erzählliteratur des deutschsprachigen Realismus. Stuttgart: Metzler 2017, darin insb. die Einleitung. S. 4 f.

29 Zum Begriff der Epochenschwelle als Phase eines tiefgreifenden Bedeutungswandels, in der bestehende Topoi, Werte und Begriffe mit neuen Bedeutungen angefüllt werden, vgl. Koselleck; Herzog (Hrsg.): Epochenschwelle und Epochenbewusstsein und Steinwachs, Burkhart: Was leisten (literarische) Epochenbegriffe? Forderungen und Folgerungen. In: Gumbrecht, Hans Ulrich; Link-Heer, Ursula (Hrsg.): Epochenschwellen und Epochenstrukturen im Diskurs der Literatur- und Sprachhistorie. Frankfurt a. M.: Suhrkamp 1985. S. $312-323$.

30 Vgl. Schneider: Gesellschaftliche Modernität und ästhetischer Anachronismus. Zur geschichtsphilosophischen und gattungsgeschichtlichen Grundlage des idyllischen Epos. S. 13-24 und Michler: Kulturen der Gattung. Poetik im Kontext 1750-195o. S. 19-86.

Vgl. Michler: Kulturen der Gattung. Poetik im Kontext 1750-195o. S. 192 f. 
Unsicherheitsbekundungen aufzuzeigen. Interessant für die hier verfolgten Thesen ist allerdings vor allem, dass es gerade das Epos ist, das in Phasen gesellschaftlicher Verunsicherung und Neuorientierung besonders attraktiv bzw. strittig wird. Bereits die erste fundamentale Gattungspoetik findet ihren historischen Ursprung in der Ordnung der sozialen Welt begründet, wie Aristoteles' in der Poetik proklamiertes Organisationsprinzip verdeutlicht:

\begin{abstract}
Was die erzählende [...] Dichtung angeht, so ist folgendes klar: man muss die Fabeln [...] so zusammenfügen, dass sie [...] sich auf eine einzige, ganze und in sich geschlossene Handlung mit Anfang, Mitte und Ende beziehen, damit diese, in ihrer Einheit und Ganzheit einem Lebewesen vergleichbar, das ihr eigentümliche Vergnügen bewirken kann. ${ }^{32}$
\end{abstract}

Im Begriff des Lebewesens wird das Epos hier mit der Vorstellung einer spezifisch anthropologisch-organischen Verfasstheit der Darstellung verbunden, wodurch es schon früh auf die Stiftung eines übergreifenden, verbindlichen Zusammenhangs ausgerichtet wird. Obwohl Aristoteles die Tragödie als die erhabenere Gattung ansieht, schafft er doch die Grundvoraussetzung für die spätere Nobilitierung und Aristokratisierung des Epos. Diesem weist er das "heroische Versmaß"33 des Hexameters zu, welches das "feierlichste und erhabenste unter allen Massen“34 sei. Weiter bestimmt er es, analog zur Tragödie, als die „Nachahmung guter Menschen“35 und führt das Gelingen dieser Nachahmung auf die ethisch-moralische Veranlagung des Dichters zurück: „Die Dichtung hat sich hierbei nach den Charakteren aufgeteilt, die den Autoren eigentümlich waren. Denn die Edleren ahmten gute Handlungen und die von Guten nach, die Gewöhnlicheren jedoch die von Schlechten $[\ldots]]^{“ 36}$ In diese Kategorie gehört zweifellos Homer, den er für „de[n] vorzüglichste[n] Dichter [für das Edle] “37 hält und der ihm „im Vergleich zu den anderen Epikern als göttlich“" ${ }^{\text {“3 }}$ erscheint - damit werden Illias und Odyssee als die ersten kanonischen Epen etabliert und Homer wird zum lange unangefochtenen Ideal erhoben.

Die nachfolgende Gattungspoetik der römischen Antike hält zunächst an Homer als Großmeister des Epos fest. Bereits in der Spätantike gibt es

32 Aristoteles: Poetik, aus dem Griech. übersetzt und hrsg. v. Manfred Fuhrmann. Stuttgart: Reclam 2006. § 23, S. 77 .

33 Ebd. $§ 24$, S. 81 .

34 Ebd.

35 Ebd. $\S 5$, S. 17 .

36 Ebd. $§ 4$, S. 13 .

37 Ebd.

38 Ebd. §23, S. 77 . 
Bestrebungen, die drei Stilarten der klassischen Rhetorik mit den drei Hauptgattungen der Literatur und den drei Ständen der Gesellschaft zu parallelisieren und damit die kulturelle Entwicklung des Menschen abzubilden. Um das Jahr 1250 ordnet dann der englische Philologe Johannes de Garlandia die Sprechlagen des niederen, mittleren und höheren Stils nicht nur den mittelalterlichen Ständen, sondern darüber hinaus den kanonbildenden Hauptwerken Vergils zu - der Bucolica, der Georgica und der Aeneis. Mit diesem Vergilischen Rad (rota Vergilii) wird die Auffassung, dass Vergil ein Weltweiser gewesen sei und sich dessen höhere Einsicht in seinem Werk widerspiegeln würde, wirkungsmächtig im gesamten europäischen Kulturraum verankert. ${ }^{39}$ Die Ablösung von Homers eher schlichten Illias durch Vergils künstlerisch komplexer gestaltete Aeneis als Gattungsideal führt zur Konsolidierung der spezifischen Konnotation zwischen aristokratischer Gesellschaftsschicht und der poetologischen Bewertung des Epos als höchster literarischer Form. Aeneas entstammt einem Herrschergeschlecht und erfüllt sein Schicksal durch Staatsgründung und Erneuerung des angeborenen Herrschaftsanspruchs, während Achilles zwar ebenfalls einem Königshaus entstammt, seinerseits aber ein kriegerisches Heldenschicksal erfüllt. Die als prototypisch bewerteten Gattungsvorbilder - zunächst Homers und dann Vergils, aber auch alle nachfolgenden - tragen diese soziale Konnotation fortan in sich, selbst dann, wenn die soziale Kategorie brüchig zu werden droht oder ihre Gültigkeit sogar bereits verloren hat, wie im Weiteren noch aufgezeigt werden soll.

Umgekehrt regulieren literarische Gattungen über ihre generischen Produktions- und Bewertungsregeln die Ausbildung und Formierung von sozialen Kategorien - ja, überhaupt tragen sie zur diskursiven Konstitution von Wissen bei. Gattungsdebatten erweisen sich deshalb als prädestinierte Verhandlungsorte von gesellschaftlichen Veränderungen und politischen Positionen. Dem Epos kommt in diesem Zusammenhang eine wichtige Rolle zu, trägt es doch wesentlich zur Stabilisierung der Aristokratie und zu deren Selbstbild wie auch Ansprüchen bei. Darüber hinaus hat es bereits in der Antike öffentlichkeitsherstellende Funktionen - das Proömium diente etwa dazu, den Vortragenden als jemanden zu etablieren, der zum öffentlichen Sprechen berechtig ist und das Publikum gleichzeitig wohlwollend stimmen soll. Diese alten Kodierungen werden in der Poetologie Epos trotz zahlreicher Überschreibungen und Kontrakodierungen aufrechterhalten, was der Gattung zu einer gewissen Konformität und gleichzeitig zu einer gattungsinternen Mehrdimensionalität gereicht, die sie bis in die Gegenwart produktiv und anschlussfähig hält.

39 Michler: Kulturen der Gattung. Poetik im Kontext 1750-195o. S. 194. 


\section{Die Gattungsdifferenzierung des 19. Jahrhunderts im Zeichen soziopolitischer Identitätsbegründung: Volksepos und bürgerliches Epos}

Geradezu exemplarisch ist das Epos in der 2. Hälfte des 19. Jahrhunderts an der Bildung und Konsolidierung nationaler Identitäten beteiligt, es ist die "große Zeit der historisierenden und idyllisierenden Epik“40 im Zeichen des Politischen, wie Michler festhält. Diese Zuwendung zum Epos lässt sich zum einen im gesamten europäischen Kulturraum als Strategie beobachten, die arbeitsteiligen Gesellschaften der neugeschaffenen Nationalstaaten als vermeintliche oder tatsächliche Traditionsgemeinschaften $\mathrm{zu}$ verankern. ${ }^{41}$ Und zum anderen stehen diese Bemühungen in Deutschland auch dezidiert im Zusammenhang mit dem Projekt, eine neue deutsche Nationalliteratur zu schreiben. Bereits seit der Mitte des 18. Jahrhunderts verfestigt sich in Deutschland die Selbstwahrnehmung einer verspäteten Nation, ${ }^{42}$ deren literarische Blütezeit sich im Gegensatz zu den anderen, sich zunehmend national ausprägenden Literaturen im europäischen Raum nicht einstellen will. In den turbulenten Jahren um und nach der Märzrevolution von 1848 tritt die poetologische Diskussion um eine eigene Nationalliteratur dann in eine deutlich ideologisch-politisch geprägte Phase ein ${ }^{43}$ in der gerade das Epos als prädestinierte Volks- bzw. Nationalgattung konstituiert wird, der bewusst Funktionen der kollektiven Identitätsstiftung ein- und zugeschrieben werden. Die nationalistische und populistische Epik der Gründerzeit ${ }^{44}$ prägt die Gattung im Sinne einer Ursprungsüberlieferung des Deutschen Volkes aus und schließt explizit an Herders frühromantischen Begriff der Volkspoesie an. Stoffe

$40 \quad$ Ebd. S. 199.

41 Urban, Urs: Die Funktion des Epischen für die Bewältigung kollektiver Niederlagen in der deutschen und französischen Literatur des 19. Jahrhunderts. In: Krauss; Mohnike (Hrsg.): Auf der Suche nach dem verlorenen Epos. Ein populäres Genre des 19. Jahrhunderts. S. $15^{-} 37$ und Taterka, Thomas: Die Nation erzählt sich selbst. Zum europäischen Nationalepos des 19. Jahrhunderts. In: Detering, Heinrich; Hoffmann, Torsten et al. (Hrsg.): Nationalepen zwischen Fakten und Fiktionen: Beiträge zum Komparatistischen Symposium, 6. bis 8. Mai 2010 Tartu (= Humaniora. Germanistica, 5). Tartu: Tartu University Press 2011. S. 20-72.

42 Vosskamp: Klassik als Epoche. Zur Typologie und Funktion der Weimarer Klassik. S. 493514, hier S. 5 o6.

43 Willems: „Ihr habt jetzt eigentlich keine Norm, die müsst ihr euch selbst geben“. Zur Geschichte der Kanonisierung Goethes als „klassischer deutscher Nationalautor“. S. 103134, hier S. $119 \mathrm{f}$.

44 Gemäß Christian Jansen eine Ära des Bürgertums und der „Verbürgerlichung der deutschen Gesellschaften“, vgl. Jansen, Christian: Gründerzeit und Nationsbildung 18491871 (= Seminarbuch Geschichte, 3253). Paderborn: Schöningh 2009. S. 242. 
und Motive der eigenen germanischen und mittelalterlichen Vergangenheit werden in gebundener, aber einfacher, an Mündlichkeit orientierter Sprache publikumswirksam aufgearbeitet. ${ }^{45}$ Nachvollziehen lässt sich das etwa an der exponentiell ansteigenden Nibelungenrezeption, aber auch an Arnims und Brentanos Des Knaben Wunderhorn sowie den Kinder- und Hausmärchen der Brüder Grimm, die sich als Sammlung und Rekonstruktion vorgeblich uralter, nationaler Erzählungen darstellen. ${ }^{46}$

Bei Herder gründete der Volksbegriff noch auf der unpolitischen, viel allgemeiner verfassten anthropologisch-philosophischen Vorstellung einer einfachen und naturhaften Gemeinschaft, die sich ursprünglich in erster Linie durch regionale, kulturelle und zeitliche Eigenarten ausprägte. ${ }^{47}$ Erst durch die „Intellektuellenbewegungen“ der Aufklärung und des Humanismus, wie Herder sie bezeichnet, wird die ursprüngliche Volksgemeinschaft von einer gelehrten Intelligenzia abgespalten und in die humanistische Standesideologie überführt, in der „der ehrwürdige Name des Volkes“ zum blossen „P̈̈bel“ abgesunken sei. ${ }^{48}$ Die von Herder als fatal beurteilte soziale Dichotomie zwischen Volk und Gelehrten gründet auf der diagnostizierten Entfremdung der bürgerlichen Gesellschaft von der Natur durch ihre unsinnliche Vernunftkultur ${ }^{49}$ und zieht bis in die Romantik weitreichende Konsequenzen für das Literatursystem nach sich. „Zum großen Nachteil der Theorie von den Dichtarten vernachlässigt man oft die Unterabteilungen der Gattungen“, bringt Friedrich Schlegel diese etwa auf den Punkt. „So teilt sich [...] die Volkspoesie in die Volkspoesie für das Volk und in die Volkspoesie für Standespersonen

45 Michler: Möglichkeiten einer literarischen Gattungspoetik nach Bourdieu. Mit einer Skizze zur ,modernen Versepik‘. S. 189-206, hier S. 199.

46 Detering, Heinrich; Hoffmann, Torsten et al.: Nationalepen zwischen Fakten und Fiktionen. Zur Einführung. In: Dies. (Hrsg.): Nationalepen zwischen Fakten und Fiktionen: Beiträge zum Komparatistischen Symposium, 6. bis 8. Mai 2010 Tartu. S. 9-19, hier S. 10. Willems: „Ihr habt jetzt eigentlich keine Norm, die müsst ihr euch selbst geben“. Zur Geschichte der Kanonisierung Goethes als „klassischer deutscher Nationalautor“. S. 103134, hier S. 113 .

48 Zitiert nach Michler: Kulturen der Gattung. Poetik im Kontext 1750-1950. S. 228.

49 Herder in der Abhandlung über den Ursprung der Sprache (1772): „Es ist für mich unbegreiflich, wie unser Jahrhundert so tief in die Schatten, in die dunklen Werkstätten des Kunstmäßigen sich verlieren kann, ohne auch nicht einmal das weite, helle Licht der uneingekerkerten Natur erkennen zu wollen. Aus den größesten [sic] Heldentaten des menschlichen Geistes, die er nur im Zusammenstoss der lebendigen Welt tun und äußern konnte, sind Schulübungen im Staube unserer Lehrkerker, aus den Meisterstücken menschlicher Dichtkunst und Beredsamkeit Kindereien geworden, an welchen greise Kinder und junge Kinder Phrases lernen und Regeln klauben." HW 1. S. 740. Herders Texte werden soweit vorhanden nach der Frankfurter Gesamtausgabe zitiert (mit Sigle HW gefolgt von Bandnummer und Seitenzahlen). 
und Gelehrte. ${ }^{40}$ Die neuen politischen Begriffe von Volk und Nation werden jetzt reflexartig auch zu den ausschlaggebenden Kategorien für die neue Literatur - und mit ihnen die angesichts der sozialen Ausdifferenzierung und Aushöhlung der ständischen Hierarchie gestellte Forderung nach dem Spezifischen, Lokalen und Zeitgemäßen. Nun, da alle Literatur in erster Linie „Sekular- und Nationalliteratur" ${ }^{451}$ sein soll, erweist sich das Volk, „das mehr Sinne und Einbildung hat, als der studierende Gelehrte ${ }^{52}$, als die eigentliche kulturrelevante Größe. Aus diesem "großen ehrwürdigen Teil des Publikums“53 soll sich die wahre, zeitgemäße Dichtkunst speisen, und für die traditionell als volksnahe gehandelte Gattung des Epos gilt das in besonderem Maße. ${ }^{54}$ Homer war für Herder nichts Anderes als der erste Volksdichter gewesen. Ihm nachzueifern, bedeutet deshalb gerade nicht, eine zwar vorbildliche, aber zeitlich sowie räumlich weitentfernte antike Literatur mimetisch nachzubilden, sondern aus der natürlich-eigenen, charakteristischen Kultur und sinnlichen Sprache zu schöpfen.

Die "trivialen Versepen“55 in der Tradition von Volkslied, Märchen und Sagen, die programmatisch eine ursprüngliche deutsche Volksidentität transportieren, erweisen sich in der Mitte des 19. Jahrhunderts als äußerst beliebt und produktiv, was wiederum die hohe politische Unsicherheit und das gesellschaftliche Bedürfnis nach einer identitätsstiftenden Literatur zu diesem Zeitpunkt belegt. Darin eingeschrieben sind gleichwohl die soziale Differenzierung in eine proletarische Arbeiterschicht und eine bürgerliche Gelehrtenschicht, die auf den bereits im revolutionären Umfeld von 1848 virulent werdenden Begriff der Klasse zurückgeht, sowie die parallel dazu weiterlaufende Spaltung der literarischen Gattungen in eine volksnahe

50 KFSA I, 2. S. 165. Friedrich Schlegels Texte werden soweit vorhanden nach der Kritischen Friedrich Schlegel-Ausgabe zitiert (mit Sigle KFSA gefolgt von Abteilungsnummer, Bandnummer und Seitenzahlen).

$5^{1}$ HW 1. S. 219.

$5^{2}$ HW 2. S. 49 o.

53 Ebd.

54 Michler: Kulturen der Gattung. Poetik im Kontext 1750-1950. S. 228 f. Herder führt die Poesie und damit auch das Epos zentral auf die Sprache, das Lied, den Gesang zurück. Aus der Einleitung zum zweiten Teil seiner Volksliedsammlung: „Es ist wohl nicht zu zweifeln, dass Poesie und insbesondere Lied im Anfang volksartig, d.i. leicht, einfach, aus Gegenständen und in der Sprache der Menge sowie der reichen und für alle fühlbaren Natur gewesen." (HW 3. S. 230). In den Metren der Gesänge sieht er sprachlich-nationale Eigenheiten ausgeprägt, nicht zuletzt deshalb fordert er auch für das Volksepos der Deutschen eine der deutschen Sprache entsprechende Metrik, anstatt griech. Hexameter.

55 Ders.: Möglichkeiten einer literarischen Gattungspoetik nach Bourdieu. Mit einer Skizze zur ,modernen Versepik‘. S. 189-206, hier S. 199. 
Trivialliteratur zum einen und eine akademisch-elitäre Poetik ${ }^{56}$ zum anderen, die sich in den jeweilig entgegengesetzten Ausprägungen von Kunst- und Volkspoesie manifestieren. Das Volk, das in Herders Fragmenten noch den Charakter einer produktionsästhetischen Stilkategorie hatte, wird im Volksepos zwar als eigene soziale Klasse im Zeichen einer spezifisch deutschen Nationalidentität konstituiert, geht seiner kulturtragenden Bedeutung jedoch verlustig.

Im ausgehenden 19. Jahrhunderts scheinen die sprachlich anspruchsvollen, stilistisch komplexen Versepen - zumindest auf den ersten Blick - verschwunden, gerät die Produktion von gravitätischer Epik seitens intellektuell-bürgerlicher Produzenten durch die populistische, leichter zugängliche Volksepik der Gründerzeit doch zunehmend in Legitimierungsnöte. Das an die antiken Kodierungen des hohen Stils und des adligen Personals anschließende Versepos bleibt jedoch als gattungsinterne Opposition zum immer mehr trivialen und prosaischen Volksepos weiterbestehen, mehr noch wird es geradezu zur Paradegattung des gebildeten Mittelstandes: ${ }^{57}$ Als stets bevorzugtes Objekt der Altphilologie läuft der im 19. Jahrhundert akademisch besonders hoch gewichtete altsprachliche Gymnasialunterricht in erster Linie über die kanonisierte Gattungsgeschichte des Versepos. Die Stilisierung Goethes zum Nationalautor und die Doktrin einer zwar späten, aber umso bedeutsameren genuinen, deutschen Klassik nehmen in der unruhigen Gründerzeit ebenfalls deutlich politisch-nationalistische Züge an. Dazu gehört auch eine sukzessive, von der Literaturgeschichtsschreibung des späten 19. Jahrhunderts systematisch betriebene, zeitliche und personelle Verkürzung der „klassischen Epoche“ von einem zunächst noch historisch relativ weiten Zeitraum, der die Aufklärung und ihre Akteure miteinschloss, auf die gut zehn Jahre dauernde, gemeinsame Wirkungszeit Goethes und Schillers in Weimar. ${ }^{58}$ Wobei gerade Goethes episches Werk und besonders Hermann und Dorothea immer wieder zur Bestimmung einer ewigen Idee des Deutschen Wesens herangezogen werden. ${ }^{59}$ So werden einerseits die prototypischen, gattungsdefinierenden Epen für jede Schülergeneration neu kanonisiert und

$56 \quad$ Ders.: Kulturen der Gattung. Poetik im Kontext 1750-195o. S. 444.

57 Vgl. Schneider: Gesellschaftliche Modernität und ästhetischer Anachronismus. Zur geschichts-philosophischen und gattungsgeschichtlichen Grundlage des idyllischen Epos. S. 13-24.

$5^{8}$ Vosskamp: Klassik als Epoche. Zur Typologie und Funktion der Weimarer Klassik. S. 493514, hier S. $506 \mathrm{f}$.

59 Vgl. Willems: „Ihr habt jetzt eigentlich keine Norm, die müsst ihr euch selbst geben“. Zur Geschichte der Kanonisierung Goethes als „klassischer deutscher Nationalautor“. S. 103134, hier S. 119 f. und Schneider: Idyllisches Epos im 19. Jahrhundert. S. 15. 
andererseits werden dadurch auch die hierarchische Gattungswertung und soziale Klassifizierung des Epos aufrechterhalten - sprich als hochsprachlichpoetische Kunstform des Bildungsbürgertums institutionell erneuert. ${ }^{60}$

Diese alternative Ausprägung des Epos erlebt allerdings eine entscheidende formale Transformation: Anstatt eines götter- und heldenbevölkerten Kosmos entstammen Personal und Motive nun der überschaubaren, häuslichen Bürgerwelt. Diese Fokussierung auf die regional und epochal charakteristischen Ausprägungen, das sich Einlassen auf Geschichte, Sitte und Lebensform der Deutschen entspricht zwar Herders Forderung, mehr aus dem NationalEigenen zu schöpfen, ist aber gerade auch in der von ihm als naturfern disqualifizierten, modernen Gesellschaft verankert. Gleichzeitig konfiguriert sie die Poetik der Idylle des 19. Jahrhunderts, in der die affektiven Bindungen der bürgerlichen Kleinfamilie das antike Schäferleben abgelöst haben. ${ }^{61}$ Schon Humboldt nannte diese neue hybride Gattungsausprägung in seiner Abhandlung zu Goethes Hermann und Dorothea folgerichtig ein bürgerliches Epos ${ }^{62}$ und Schiller sprach seinerseits ebenfalls von der bürgerlichen Idylle ${ }^{63}$ - neben Hermann und Dorothea gilt auch Voß' Luise als prototypisch für die frühen bürgerlich-idyllischen Epen. Beide Texte avancieren in kürzester Zeit zu „Lieblingsbüchern der Bürger des 19. Jahrhunderts"64 und Helmut Schneider zählt bis zur Jahrhundertmitte an die vierzig Werke, die an Goethe und Voß anschließen, von denen Mörikes Idylle vom Bodensee (1846) und Hebbels Mutter und Kind (1859) - beide Hexameter-Gedichte, die eine heile, harmonische kleine Welt darstellen - die bekanntesten sind. ${ }^{65}$ Meist handelt es sich dabei um verklärte Darstellungen eines unaufgeregten Alltags gebildeter Lehrer- und Pfarrerfamilien, die nur über den Rand ihrer kleinen Welt hinausschauen, um es dann doch drinnen entschieden besser zu finden als draußen. Dennoch enthalten diese Texte teilweise eine massive Gesellschaftsideologie, die gerade die Familie, deren Struktur sich im späten 18. Jahrhundert von der

6o Vgl. hierzu auch Schneider: Gesellschaftliche Modernität und ästhetischer Anachronismus. Zur geschichts-philosophischen und gattungsgeschichtlichen Grundlage des idyllischen Epos. S. 13-24, hier S. 14.

61 Böschenstein, Renate: Idyllisch / Idylle. In: Barck, Karlheinz; Fontius, Martin et al. (Hrsg.): Ästhetische Grundbegriffe. Historisches Wörterbuch in sieben Bänden, Bd. 3. Stuttgart: Metzler 2001. S. 119-138, hier insb. S. 124-131.

62 Humboldt: Ueber Göthes Herrmann und Dorothea (1799). S. 138.

63 Schiller, Friedrich: Nationalausgabe. Briefwechsel. Schillers Briefe. 1.7.1795-31.10.1796, hrsg. v. Norbert Oellers, Bd. 28. Wien, Köln, Weimar: Böhlau 1969. 323 .

64 Böschenstein: Idyllisch / Idylle. S. 119-138, hier S. 127.

65 Vgl. Schneider: Gesellschaftliche Modernität und ästhetischer Anachronismus. Zur geschichts-philosophischen und gattungsgeschichtlichen Grundlage des idyllischen Epos. S. 13-24, hier S. 13 . 
vorindustriellen Groß- zur bürgerlichen Kleinfamilie wandelt, nun als natürliches Vorbild gesellschaftlicher Ordnung begreift und deren Werte - Familie, Besitz und Bildung - als universale Grundwerte der modernen, arbeitsteiligen Gesellschaft festschreibt. ${ }^{66}$

\subsection{Hegel: Bürgerlicher Weltzustand und der Tod des Epos}

Die Vermischung des Epos mit der Idylle gereicht Hegel gut 20 Jahre nach Voß und Goethe bekanntlich zum Ausgangspunkt für seine epochemachende Verabschiedung des Epos aus der zeitgenössischen Literatur. Mit der szenischthematischen Reduktion auf die bürgerlichen Zustände auf dem Land oder in der Kleinstadt habe sich die echte „eigentliche Epopöe“ gerade „bei uns Deutschen“ in die schützende Beschränktheit der Idylle geflüchtet. ${ }^{67}$ Die Idylle als „untergeordnete[r] Nebenzweig [...] des eigentlich Epischen“ sieht in ihrer modernen Ausprägung von "allen tieferen allgemeinen Interessen des geistigen und sittlichen Lebens ab" und stellt „den Menschen in seiner Unschuld“68 dar. Dieser unschuldige Zustand kommt gemäß Hegel einer voraufklärerischen Unmündigkeit gleich, in dem die Menschen

von nichts wissen als von Essen und Trinken, und zwar von sehr einfachen Speisen und Getränken, [...]. Ihre Beschäftigung nun besteht darin, diesem lieben Vieh mit dem treuen Hunde den ganzen lieben Tag lang aufzupassen, für Speise und Trank zu sorgen und nebenher mit so vieler Sentimentalität als möglich solche Empfindungen zu hegen und zu pflegen, welche diesen Zustand der Ruhe und Zufriedenheit nicht stören, d.h. in ihrer Art fromm und zahm zu sein, auf der Schalmei, der Rohrpfeife usf. zu blasen oder sich etwas vorzusingen und vornehmlich einander in grösster Zartheit und Unschuld liebzuhaben. - Die Griechen dagegen hatten in ihren plastischen Darstellungen eine lustigere Welt $[\ldots]$ als jene prätentiöse Unschuld, Frömmigkeit und Leerheit. ${ }^{69}$

Vom wahren Epos sei dieses in süßlich-sentimentalischer Künstlichkeit konservierte Bruchstück nun jedoch weit entfernt, bringe das echte Epos, „indem es zum Gegenstande hat, was ist“ doch die „ganze Breite der Umstände und Verhältnisse als reiche Begebenheiten im Zusammenhang mit der in

66 Ebd. S. 15 u. 23.

67 Hegel, Georg Wilhelm Friedrich: Vorlesungen über die Ästhetik III. Frankfurt a. M.: Suhrkamp 1989. S. 414.

68 Ebd. S. 390 f.

69 Ebd. S. 391. 
sich totalen Welt einer Nation und Zeit zur Anschauung “. ${ }^{70}$ Wohingegen die moderne Idylle bezüglich der Frage ihrer gesellschaftlichen Potenziale bereits seit Schiller familiale Gemeinschaften ohne sichtbare Beziehungen zu den komplexen staatlichen Gebilden darstellt und insofern im Kontext sentimentalisch-utopischer, idealer Modelle steht. ${ }^{71}$ „[D]en Inhalt und die Form des eigentlich Epischen [macht deshalb] [die gesamte Weltanschauung und Objektivität eines Volksgeistes] [...] aus"72 und nicht nur ein kleiner, verklärter Ausschnitt davon. Damit erfindet Hegel das Epos gewiss nicht neu, vielmehr gelten Totalität, Breite und Objektivität schon lange als die ausgemachten Eigenschaften der Gattung. Bemerkenswert ist an Hegels Ästhetik jedoch die systematische Einordnung des derart bestimmten Epos in ein streng lineares, geschichtsphilosophisches Konzept, welches Gattungsbegriffe und Epochenprofile, philosophische Weltanschauung und politisches Gesellschaftsbild in ein Entsprechungsverhältnis setzt. So begründet Hegel seinen Abgesang auf das Epos mit dem gegenwärtigen „vernünftigen“ „Weltzustand“, dessen „prosaische Ordnung“ die Möglichkeit eines echten, heroischen Epos in der Moderne grundsätzlich zunichtemacht. ${ }^{73}$ Denn:

Unser heutiges Maschinen- und Fabrikenwesen mit den Produkten, die aus demselben hervorgehen, sowie überhaupt die Art, unsere äußeren Lebensbedürfnisse zu befriedigen, würde [...] ebenso als die moderne Staatsorganisation dem Lebenshintergrunde unangemessen sein, welchen das ursprüngliche Epos erheischt. / Denn wie der Verstand [...] in den Zuständen der eigentlich epischen Weltanschauung sich noch nicht muss geltend gemacht haben, so darf hier auch der Mensch noch nicht von dem lebendigen Zusammenhange mit der Natur und der kräftigen und frischen, teils befreundeten, teils kämpfenden Gemeinschaft mit ihr losgelöst erscheinen. ${ }^{74}$

Totalität, Einheit und Ursprünglichkeit sind der „heutigen“ Welt abhandengekommen, das Subjekt hat sich durch seine kritische Reflexionstätigkeit zwar auf eine höhere geistige Entwicklungsstufe gehoben, sein unschuldiges Verhältnis zur Natur, zur Welt und letztlich auch zur Gesellschaft ist dadurch jedoch unumkehrbar ein komplexes, diskontinuierliches und disparates geworden: Der menschliche Geist hat sich von einem subjektiven, in sich ruhenden zu

70 Ebd. S. 330.

71 Böschenstein: Idyllisch / Idylle. S. 119-138, hier S. 126 f.

72 Hegel: Vorlesungen über die Ästhetik III. S. 33o.

73 Ebd.

74 Ebd. S. 341. 
einem objektiven, sich selbst als gegenständlich wahrnehmenden entwickelt. ${ }^{75}$ Diese Vorstellung des sich selbst und vor allem seiner individuellen Bedürfnisse bewusst gewordenen, berechnenden Menschen ist auch der zentrale Ausgangspunkt von Hegels soziopolitischer Theorie der modernen bürgerlichen Gesellschaft, die er als frühkapitalistische Klassengesellschaft definiert. ${ }^{76}$ Der Ausgang aus der Unmündigkeit und die daraus entstandene, arbeitsteilige Gesellschaftsform haben nicht zuletzt auch gravierende Konsequenzen für die Kunst. Denn das wahre, vom Menschen geschaffene Schöne ist gemäß Hegel kein bewusst reflektiertes Vernunft-Produkt, sondern eine intuitiv-natürliche Hervorbringung des subjektiven menschlichen Geistes: Der Geist schaut sich an, bedient sich unwillkürlich der Natur, um sich selbst auszudrücken,

75 In aller Kürze: In Hegels Terminologie sind die Begriffe der Objektivität und des objektiven Geistes - und entsprechend Subjektivität und subjektiver Geist - nicht deckungsgleich. Das Epos erfüllt das Kriterium der Objektivität, weil der Dichter darin nicht als Subjekt erscheint, es zeigt gleichgültig Allgemein-Menschliches. Die Subjektivität definiert Hegel als das für sich selbst Seiende, etwas Eigenes, Selbstständiges. Der subjektive Geist allerdings sei die natürliche, erste geistige Entwicklungsstufe des Menschen, hier finde noch kein abstraktes Denken statt. Erst ein objektiver, distanzierter Geist kreiere abstrakte Denksysteme - Moral, Sittlichkeit, Rechtsdenken und entsprechend soziale Institutionen, politische Modelle. Die Differenzierung von subjektivem/objektivem Geist und daran anschließend die Systematisierung des objektiven Geistes sind grundlegend für Hegels Begriff der bürgerlichen Gesellschaft, vgl. Hortsmann, Rolf-Peter: Über die Rolle der bürgerlichen Gesellschaft in Hegels politischer Philosophie (= Hegel-Studien, Bd. 9). Berlin: Humboldt-University 1974. S. 1.

76 Vgl. Hegel, Georg Wilhelm Friedrich: Grundlinien der Philosophie des Rechts oder Naturrecht und Staatswissenschaft im Grundrisse. Mit Hegels eigenhändigen Notizen und den mündlichen Zusätzen. Frankfurt a. M.: Suhrkamp 2015. Vgl. dazu auch Riedel, Manfred: Hegels Bürgerliche Gesellschaft und das Problem ihres geschichtlichen Ursprungs. In: Internationale Vereinigung für Rechts- und Sozialphilosophie (Hrsg.): Archiv für Rechtsund Sozialphilosophie, Bd. 48. Stuttgart: Steiner 1962. S. 539-566. Der Bürger-Begriff durchläuft in der Neuzeit mehrere Bedeutungswandel - um 1700 ist damit noch der StadtBürger gemeint, in rechtlicher Abgrenzung zum Landbewohner-Untertan, in der Goethezeit prägt sich dann die staatsbürgerliche Bedeutung aus als politischer Gegenbegriff zu aristokratischer Obrigkeit und Reaktion auf die sich auflösende Ständeordnung. Dieses Bürgertum definiert sich über kulturelle Gestaltung des Zusammenlebens und dessen Institutionalisierung. Der, wie bei Herder noch deutlich sichtbar, ehemals separate Stand der Gelehrten (Pfarrer, Lehrer, Professoren, Juristen) wird nun in den breiten, heterogenen Bürgerstand integriert, wozu im 19. Jahrhundert selbstverständlich auch die Handwerker, Kaufleute und andere mittlere Gewerbeschichten gehörten. Seither ist ein Begriff wie ,Bildungsbürger‘ für die Bezeichnung einer bürgerlichen Teilgruppe sinnvoll, wobei der Begriff tatsächlich erst nach dem Ersten Weltkrieg entsteht. Im 19. Jahrhundert wird der Bürger (bei Marx dann der ,bourgeois') wie sich bei Hegel gut nachverfolgen lässt, zum Klassen-Begriff der Nichtproletarier, vgl. Conze, Werner; Kocka, Jürgen et al. (Hrsg.): Bildungsbürgertum im 19. Jahrhundert, Teil 1-4. Stuttgart: Klett-Cotta 1985-1992. 
und schafft so das Kunstschöne. ${ }^{77}$ In der systemisch ausdifferenzierten, von rationalen, selbstreflexiven Individuen bevölkerten Moderne kann es allerdings diese unwillkürliche, absolute und insofern ideale Kunst nicht mehr geben. Hier wird offensichtlich, wie das konstruierte Entsprechungsverhältnis zwischen Reflexionstätigkeit, gesellschaftlichem Selbstverständnis und Kunstfähigkeit, das Hegel im Kern seiner Geschichtsphilosophie installiert, ihn schließlich zu seiner epochemachenden These vom „Ende der Kunst“ führen muss.

In Hegels kulturpessimistischem Geschichts- und Kunstverständnis nimmt nun das Epos insofern eine zentrale Stellung ein, als es im Rückblick als ein verlorenes Ideal vergangener Zeit stilisiert wird, in dem der Mensch gerade erst "aus der Dumpfheit erwacht" ${ }^{48}$ und noch in der Welt geborgen war. In dieser vormodernen Epoche, namentlich der griechischen Antike, verortete Hegel jenen ersten poetischen, „epischen Weltzustand“, in dem der Mensch noch in einem unreflektiert-unmittelbaren, natürlichen Verhältnis zu sich und der Welt stand und diese objektive Einheit in einer entsprechend noch wahrhaften Kunst ${ }^{79}$ zur Anschauung brachte. Das homerische Epos gilt Hegel als Inbegriff dieser Epoche, ihrer Gesellschaftsform und Kunstausprägung, insofern schließt er an die von Winckelmann und Friedrich W. J. Schelling begründete Griechenverehrung des Klassizismus ${ }^{80}$ an. Ähnlich wie Winckelmann misst auch Schelling dem antiken Epiker einen quasi göttlichen Status bei, er sieht ihn als Dichter „von solcher Größe, dass keine spätere Zeit ihm Ähnliches hervorzubringen im Stande war".81 Bei Schelling ist Homer aber weit mehr als nur ein Autor, er gerät geradezu zum Geschichtsprinzip: „Der homerische Mythos, und insofern Homer selbst, [ist] in der griechischen Poesie absolut das Erste und der Anfang. ${ }^{42}$ Aus dieser kunstphilosophischen Position erscheint Homer als der Ursprung von allem - der Menschheit, der Dichtung, der Geschichte. In ihm drückt sich der glückliche Geisteszustand

77 Vgl. Liggieri, Kevin: Warum gelingt uns das Epische so selten? Ein Blick hinter Goethes Achilleis. Berlin: Wvb 2010. S. 47.

78 Hegel: Vorlesungen über die Ästhetik III. S. 332.

79 Zu Hegels Kunstbegriff: Kunst ist die Art und Weise, wie das Göttliche - die tiefsten Interessen der Menschen und die umfassendsten Wahrheiten des Geistes - zu Bewusstsein gebracht wird. Kunst ist also Selbstanschauung bzw. der Ausdruck des sich selbst betrachtenden Geistes. Kunst als eigentätige Produktion der geistigen Manifestation - der Geist schaut sich an, bedient sich dabei der Natur und schafft so das Schöne: die Kunst. Der hohe Stellenwert von Einheit und Totalität ist für diesen Kunstbegriff offensichtlich.

$80 \quad$ Vgl. S. 42 ff. in diesem Buch.

81 Schelling, Friedrich Wilhelm Joseph von:Schriften zur Religionsphilosophie. In:Schellings Werke, hrsg. v. Karl Friedrich August Schelling, Bd. 6. Stuttgart: Beck 1779. S. 241.

82 Schelling: Philosophie der Kunst. In: Ders.: Sämtliche Werke, hrsg. v. Karl Friedrich August Schelling, Bd. 5. Stuttgart und Augsburg: Cotta 1859. S. 353-736, hier S. 410. 
der Menschheit und ihre unnachahmliche Kunst aus, der Dichter, sein Werk und seine Epoche erscheinen als eine Chiffre. ${ }^{83}$ Für Schelling stellt das antike homerische Epos also das höchste, ursprüngliche Kunstideal dar. Diese Überzeugung radikalisiert nun Hegel, indem er die Möglichkeit eines modernen Epos, das Wiedererlangen eines totalen, epischen Weltzustands und damit die Wiederholung einer wahrhaften, reintegrativen Kunst kategorisch negiert - da sich die Geschichte nun mal vorwärts entwickelt und das Zeitalter der kulturlosen Moderne nicht hintergangen werden, bedeutet das Ende der Kunst auch das Ende des Epos.

Mit dem Losreißen von der Natur befreit sich der Mensch von deren Zwängen und tritt gleichwohl in den von Hegel als prosaisch bezeichneten Weltzustand ein, der unverkennbar im Zeichen von individueller Subjektivität, gesellschaftlicher Partikularität und dem damit verbundenen Verlust eines verbindlichen, kulturstiftenden Kunstsystems steht. Und obwohl Hegel die Ablösung des prosaischen durch ein philosophisches Zeitalter prognostiziert, in dem der Mensch zur Selbsterkenntnis gelangt und Subjekt und Welt sich wieder annähern, wird die zukünftige Kunst dieser höchsten geistigen Entwicklungsstufe eben eine philosophische sein und die ursprünglich poetische nicht restituieren. Die vom Homerischen Epos repräsentierte totale Einheit von Natur, Mensch und Kunst ist mit dem Eintritt in die Moderne endgültig und unwiederbringlich zerstört. Gleichwohl liegt damit auch der ästhetische Höhepunkt der Menschheitsgeschichte - das Goldene Zeitalter - unerreichbar in der Vergangenheit. Die zeitgenössische Kunst sieht darin alles gespiegelt, was ihr nicht gelingt, gar nicht gelingen kann. Die Gattung des Epos erscheint in der Konsequenz als unzeitmässig und vergangen - was die moderne Welt ist, kann gar nicht als ein einheitliches Ganzes gefasst werden, eine derartige Vorstellung ist überhaupt unrealistisch, naiv - ja, eben idyllisch - geworden.

„Die Prosa des wirklichen Lebens“ ${ }^{44}$ findet hingegen ihre adäquate Darstellung nun allein im Roman, dieser „bürgerlichen Epopöe“85, die das wahre, poetische Epos abgelöst hat. Darin wird auf „die Kreise des gegenwärtigen nationalen und sozialen Lebens" ${ }^{\text {“6 }}$, ihre modernen Verhältnisse und Anforderungen Rücksicht genommen, sowohl in Bezug auf die „Lebendigkeit der Begebnisse als auch in betreff der Individuen und ihres Schicksals“. ${ }^{.87} \mathrm{Hegel}$ schreibt seiner geschichtsphilosophischen Ästhetik somit grundlegend die im

83 Wohlleben, Joachim: Die Sonne Homers. Zehn Kapitel deutscher Homer-Begeisterung. Von Winckelmann bis Schliemann (= Kleine Vandenhoeck-Reihe, 1554). Göttingen: Vandenhoeck \& Ruprecht 199o. S. 8o.

84 Hegel: Vorlesungen über die Ästhetik III. S. 393.

85 Ebd. S. 392.

86 Ebd. S. 415 .

87 Ebd. S. $392 \mathrm{f}$. 
18. Jahrhundert virulent gewordene Dialektik zwischen Epos und Roman ein, die dezidiert alles Gegenwärtige und Aktuelle als Zeichen dekadenter Kunstlosigkeit ausmacht, im Roman verortet und diesen gleichwohl als die Erzählgattung der Moderne festschreibt. Dem Epos dagegen wird jeglicher Gegenwartsbezug abgesprochen, dafür aber höchste ästhetische Qualität zugestanden. Hegel wirft einen desillusionierten Blick auf die prosaisch-trivialen Verhältnisse seiner Gegenwart und empfiehlt den modernen Menschen den ebenso trivialen, durch das zufällig-belanglose ${ }^{88}$ der Individualität und Kontingenzerfahrung gekennzeichneten Roman als Gesellschafts- und Kulturspiegel an. Nur eine Erzählung, die die Komplexität und Disparatheit der modernen Welt sowohl inhaltlich wie auch formal verarbeitet, verspricht eine gültige, zeitgemäße Aussage über die menschlichen und kulturellen Verhältnisse der Moderne machen zu können. Nun ist das Epos, gerade auch in seiner idyllischbürgerlichen Ausprägung, gewiss keine derartig progressive Gattung. Vielmehr scheint seine formimplizierte Rückgewandtheit, sein Beharren auf Einfachheit und Kontinuität, die Hegelsche Verabschiedung zu rechtfertigen und den traditionell hergestellten Zusammenhang mit einem konservativen und restaurativen Klassizismus zu bestätigen.

\subsection{Modernes Erzählen: Vom Aufstieg des Romans}

Dass modernes, zeitgemäßes Erzählen im Roman stattfindet, darüber herrscht in der Literaturwissenschaft ein seltsam unhinterfragter Konsens und die Prämisse scheint mit einem Blick in die gegenwärtigen Auslagen des Buchhandels bis heute wirksam zu sein. Wie keine andere Gattung nimmt der Roman das moderne Subjekt und seine Erfahrungswelt in sich auf und stellt sie in ihrer Vielfältigkeit dar. Diese Konzeption erlangt der Roman im Zusammenhang mit den epochalen Umwandlungen der Gesellschafts- und Glaubensvorstellungen des 18. Jahrhunderts, in deren Verlauf ihm eine wesentliche Rolle für die Ausdifferenzierungs- und Abgrenzungsprozesse des modernen Literatursystems zugesprochen wird. Die voraufklärerische Auffassung vom Roman als unmoralisch-gefährliche Gattung weicht einer Nobilitierung der Form als pädagogisch wertvoll und so wird der Roman zum exemplarischen Verhandlungsort des modernen Erzählens. ${ }^{89}$

88 Vgl. ebd. S. 243.

89 Vgl. Lämmert, Eberhard (Hrsg.): Romantheorie 1620-1880. Dokumentation ihrer Geschichte in Deutschland. Frankfurt a. M.: Athenäum 1988. S. 53; Vosskamp, Wilhelm: Romantheorie in Deutschland. Von Martin Opitz bis Friedrich von Blanckenburg 
In seiner Philippika von 1698 bezichtigt der calvinistische Pastor Gotthard Heidegger den barocken Liebes- und Abenteuerroman noch der Lüge und befindet ihn als unmoralisch. ${ }^{90}$ Der Roman gilt zu diesem Zeitpunkt allgemein als verderbliche Gattung, weil er sich mit Liebessachen beschäftige und so zur Wollust verführe, weil er mit seinen überbordenden Phantasien den Kopf verwirre und weil er Eitelkeit und Galanterie lehre - damit sei er eine Beschäftigung für Müssiggänger und verderbe den guten Geschmack. ${ }^{91}$ Im 18. Jahrhundert erscheint dann aber ein neuer Romantypus, der sich auf empfindsame und sittenstrenge Erzählungen fokussiert. Diesem wird im Gegensatz zum lasterfördernden Barockroman das Potenzial zugestanden, zu Bildung und Tugendhaftigkeit beitragen zu können und es kommt zu einer vorsichtigen moralischen Umwertung der Gattung. Gleichzeitig vollzieht sich auch ein narratologischer Paradigmenwechsel weg von den Prinzipien der metaphysischen Teleologie hin zu einer natürlichen Kausalität. Damit sind nun die Voraussetzungen für die Akzeptanz und aufklärerische Wirksamkeit des Romans gegeben, ${ }^{92}$ die mit seiner inhaltlichen Wahrscheinlichkeit und Glaubwürdigkeit ${ }^{93}$ begründet werden. Der neue Roman spielt in Bereichen, die den Lesern räumlich, zeitlich und sozial bekannt und vertraut sind, er enthält keine Phantasterei oder Anrüchigkeit wie der barocke Roman und vermittelt exemplarisch die anzustrebenden, aufklärerischen Sitten und Werte.

In der Poetik der Aufklärung folgt auf diese moralische Anerkennung des Romans auch die Frage nach seinem ästhetischen Dichtungscharakter, immer mehr wird er zum zentralen Gegenstand literaturtheoretischer Überlegungen dazu gehören die Abspaltung vom antiken Epos sowie die zunehmende Hinterfragung seines expliziten Moralisierens und seiner mittlerweile als übertrieben beurteilten Empfindsamkeit. ${ }^{94}$ Tugendhaftigkeit soll nun nicht mehr gepredigt,

(= Germanistische Abhandlungen, Bd. 40). Stuttgart: Metzler 1973. S. 121-141; Martens, Wolfgang: Die Botschaft der Tugend. Die Aufklärung im Spiegel der deutschen Moralischen Wochenschriften. Stuttgart: Metzler 1971. S. $512 \mathrm{ff}$.

90 Vgl. Lämmert: Romantheorie 1620-1880. Dokumentation ihrer Geschichte in Deutschland. S. 53 .

91 Vgl. Martens: Die Botschaft der Tugend. Die Aufklärung im Spiegel der deutschen Moralischen Wochenschriften. S. 494.

92 Vgl. Brenner, Peter J.: Die Krise der Selbstbehauptung. Subjekt und Wirklichkeit im Roman der Aufklärung (= Studien zur deutschen Literatur, Bd. 69). Tübingen: Niemeyer 1981. S. $156-165$.

93 Vgl. Lämmert: Romantheorie 1620-1880: Dokumentation ihrer Geschichte in Deutschland. S. 70-80.

94 Vgl. Jacobs, Jürgen: Prosa der Aufklärung. Moralische Wochenschriften, Autobiographie, Satire, Roman. Kommentar zu einer Epoche. München: Winkler 1976. S. 27 f.; Lämmert: Romantheorie 1620-1880: Dokumentation ihrer Geschichte in Deutschland. S. 106-120. 
sondern im konkreten Verhalten aufgezeigt werden, Charaktere sollen natürlich und nicht mehr exemplarisch fest sein, wie überhaupt die Handlung nicht mehr ein Exempel ausführen, sondern wirklichkeitsgetreu wirken soll. Das Wunderbare, das dem barocken Roman noch eigen war, wird weiter und auch immer radikaler aus dem, guten' Roman ausgeschlossen, dafür wird das Realistische immer wichtiger. Diese ästhetische Anerkennung des Romans ist mit dem Paradigma der inneren Geschichte zum einen und einem Bekenntnis zur Realität zum anderen verbunden, die sich gerade auch als die zentralen Abgrenzungspunkte gegenüber dem epischen Gattungskonzept erweisen werden. Eine detaillierte psychologische Darstellung des Inneren und die Verankerung in einer realen Umgebung sind die bestimmenden Faktoren des modernen Romans - beispielhaft realisiert in Moritz' Anton Reiser, Wielands Agathon, Goethes Meister und auch im Werther. Und diese Errungenschaften machen auch seine wirkungsästhetische Rechtfertigung als das neue Erzählen aus. ${ }^{95}$ Wieland bringt das im Vorbericht seines Agathons prägnant auf den Punkt:

Die Wahrheit, welche von einem Werke, wie dasjenige, so wir den Liebhabern hiemit [sic] vorlegen, gefordert werden kann und soll, bestehet darin, dass alles mit dem Lauf der Welt übereinstimme, dass die Character [sic] nicht willkürlich, und bloß nach der Phantasie, oder den Absichten des Verfassers gebildet, sondern aus dem unerschöpflichen Vorrat der Natur selbst hergenommen; in der Entwicklung derselben so wohl die innere als die relative Möglichkeit, die Beschaffenheit des menschlichen Herzens, die Natur einer jeden Leidenschaft, mit allen den besondern Farben und Schattierungen, welche sie durch den Individual-Character [sic] und die Umstände einer jeden Person bekommen, aufs genaueste beibehalten; daneben auch der eigene Character des Landes, des Orts, der Zeit, in welche die Geschichte gesetzt wird, niemals aus den Augen gesetzt; und also alles so gedichtet sei, dass kein hinlänglicher Grund angegeben werden könne, warum es nicht eben so wie es erzählt wird, hätte geschehen können, oder noch einmal wirklich geschehen werde. Diese Wahrheit allein kann Werke von dieser Art nützlich machen, und diese Wahrheit getrauet sich der Herausgeber den Lesern der Geschichte des Agathons zu versprechen. ${ }^{96}$

ImZentrum diesesErzählens steht ein sich individuell konstituierendesSubjekt, das, um ein glaubhafter Charakter zu sein, nicht schon von Anfang an ein Bild vollkommener Tugendhaftigkeit ist, sondern im Lauf seiner Entwicklung

95 Biere, Florentine: Das andere Erzählen. Zur Poetik der Novelle 180o/190o (= Philologie der Kultur, Bd. 6, hrsg. v. Kiening, Christian; Schneider, Sabine; von Arburg, Hans-Georg). Würzburg: Königshausen \& Neumann 2012. S. 34.

96 Wieland, Christoph Martin: Geschichte des Agathon. In: Ders.: Werke, hrsg. v. Fritz Martini und Hans Werner Seiffert, Bd. 1. München: Hanser 1964. S. 375-381, hier S. 375. 
dahin Herausforderungen bestehen muss. ${ }^{97}$ Äussere Begebenheiten sind für den Leser gemäß Wieland an sich völlig uninteressant, sie scheinen willkürlich, erst die Verbindung mit Einblicken in das Innere des erzählten Charakters macht die Erzählung sowohl fesselnd wie auch wahrscheinlich und lädt so die äußeren Begebenheiten überhaupt erst mit Bedeutung auf. ${ }^{98}$

Daran - und an Henry Fieldings Tom Jones - knüpft Friedrich von Blanckenburg 1774 mit seiner epochemachenden Romantheorie an. Er überführt Wielands Überlegungen, die er in dessen Agathon exemplarisch verwirklicht sieht, in ein straffes, normatives Programm, das für die ganze folgende Romandiskussion ausschlaggebend sein wird. Er fasst den Roman im Grunde als eine „innere Geschichte ${ }^{499}$ und sieht „den guten Roman für das an, was, in den ersten Zeiten Griechenlands, die Epopee für die Griechen war" oder zumindest glaubt er, „dass der gute Roman für uns das werden“100 und insofern „das menschliche Geschlecht seiner Vervollkommnung näher bringen“101 könnte. Die programmatische Ablösung des Epos durch den Roman erklärt er mit dem grundlegenden Wandel der Zeit:

Die Romane entstanden nicht aus dem Genie der Autoren allein; die Sitten der Zeit gaben ihnen das Daseyn [sic]. Gegenden, in welchen man keine Bürger ${ }^{102}$ brauchte; und Zeiten, in welchen keine Bürger mehr waren, verwandelten die Heldengedichte der Alten, eine Iliade oder Odyssee, in einen Roman. Der erste Romanendichter würde, wenn er in ganz bürgerlichen Zeiten geboren, und gebildet worden, an statt einen Roman zu schreiben, gewiss eine Epopee geschrieben haben. - Doch die Heldengedichte der Alten sind nicht durch diese Romane etwann so verdrängt geworden, dass sie nicht dabey [sic] haben bestehen können, und wirklich bestanden sind; sondern diese sind nur so zur Unterhaltung ihrer Zeit geschrieben worden, wie jene zur Unterhaltung der ihrigen. Den Eindruck, den damals nur jene machen konnten, machen jetzt diese; in so fern nämlich nur, dass sie die Unterhaltung des Publikums jetzt sind, so wie es jene ehmals waren. ${ }^{103}$

97 Ebd. S. 377.

98 Ebd. S. 375 .

99 Vgl. Blanckenburg, Friedrich von: Versuch über den Roman. Faksimiledruck der Originalausgabe von 1774, mit einem Nachwort von Eberhard Lämmert. Stuttgart: Metzler 1965. S. 56: „innere Bewegung“, S. 146: „innere Geschichte des König Lear“ und viele Stellen mehr.

100 Ebd. S. 13.

101 Ebd. S. 14.

102 Blanckenburg verwendet den Bürger-Begriff im Sinne des Polites der griechischen Polis, vgl. Bellen, Heinz: Polis. In: Ziegler, Konrat; Sontheimer, Walther (Hrsg.): Der neue Pauly. Lexikon der Antike, Bd. 4. München: Druckenmüller 1972. S. 976 f.

103 Blanckenburg: Versuch über den Roman. S. 13 f. 
Der aktuelle, gegenwärtige Roman stellt also nicht „öffentliche Thaten [sic] und Begebenheiten, das ist, Handlungen des Bürgers“, sondern „Handlungen und Empfindungen des Menschen "104 dar und ist ein "Gedicht, in welchem alle Handlungen dahin nur zweckten, den Geist und den Charackter [sic] eines einzelnen Mannes zu bilden“. ${ }^{105}$ Diese Anforderungen stehen in einem explizit wirkungsästhetischen Kontext: Das Vergnügen soll unterrichten, also Wissen vermitteln und erziehen. ${ }^{106}$ Der Roman soll den Menschen demnach moralisch und tugendhaft machen, indem er die innere Leidens- und Entwicklungsgeschichte eines realistischen - sprich gegenwärtigen - Helden auf unterhaltsam-fesselnde Weise zur Darstellung bringt. Weiter argumentiert von Blanckenburg ganz in Übereinstimmung mit dem zeitgenössischen wirkungsästhetischen Diskurs ${ }^{107}$, dass die Darstellung wahrnehmbarer Veränderungen den Leser mehr bewegten als statische Zustände ${ }^{108}$, weshalb der Erzähler die Handlung vorantreiben und eine Veränderung des Charakters entwickeln soll:

In den Thaten [sic] dieser Leidenschaften sehen wir nicht das, was wir sehen wollen, und was wir in dem bloßen Ausdruck erkennen, - das, was allein uns in Bewegung setzen kann: die innre Gemüthsverfassung der Person. An diesem Innern ist, wenn wir bewegt werden sollen, das mehrste gelegen. ${ }^{109}$

Überhaupt ist für von Blanckenburg eine Handlung „bloß, wie ich glaube, abwechselnder Zustand unsrer Gemüthsfassung, innerliche Bewegung “110 und jeder Dichter muss deshalb „das Innere seiner Person kennen und [...] es erzählen".111 Diese Romankonzeption der kausalverknüpften, sinnstiftenden inneren Geschichte, der inneren Bewegung als Handlungsgrundlage, der Ausrichtung auf Unterhaltung und der motivischen Verankerung in der räumlichen und zeitlichen Gegenwart bzw. Realität bestimmt die Poetik des Romans bis ins 2o. Jahrhundert und bildet gleichwohl die Folie für den Eposdiskurs um 1800. Zu diesem Zeitpunkt wird einer Prosaform überhaupt zum ersten Mal ästhetische Anerkennung in diesem Ausmaß zuteil ${ }^{112}$ - im Roman soll sich nicht nur die Moderne manifestieren, sondern gerade auch

\footnotetext{
104 Ebd. S. 17.

105 Ebd. S. 13.

106 Ebd. S. 8.

107 Biere: Das andere Erzählen. Zur Poetik der Novelle 180o/19oo. S. 37.

108 Blanckenburg: Versuch über den Roman. S. 98.

109 Ebd. S. 96.

110 Ebd. S. 56.

111 Ebd. S. 264.

112 Vgl. Jacobs: Prosa der Aufklärung. Moralische Wochenschriften, Autobiographie, Satire, Roman. Kommentar zu einer Epoche. S. 34.
} 
die besonderen Qualitäten modernen Erzählens. An dieser offensichtlich normativ interessierten Engführung lässt sich bereits ablesen, dass im Roman dann jeweils das besonders Moderne die gute Erzählung ausmacht. ${ }^{113}$ Das heißt konkret, dass trotz Disparatheit und Düsternis der Welt, der Isolation und des Ausgeliefertseins des Subjekts die aufklärerische Selbstbewusstwerdung als gelingendes Projekt einer tieferen Einsicht aufgezeigt wird. Insofern versucht der Roman, die Krise der Moderne mit dem Blick nach innen kompensatorisch zu lösen. ${ }^{114}$ Das ist sein genuiner ästhetischer Beitrag, die soziokulturellen, geschichtsphilosophischen und kunsttheoretischen Probleme zu bewältigen, was durchaus auch für die Sattelzeit von höchster Bedeutung ist: Die durch den Aufklärungs- und Säkularisierungsprozess verlustig gegangene Vorstellung von Ganzheit rettet das dominante Romanprogramm der inneren Geschichte und moralischen Erzählung ins Subjekt.

\subsection{Die Rückforderung des Epischen im 2o. Jahrhundert}

Der Aufschwung des Romans führte - zumindest vordergründig - zur Ablösung des Epos und zu der bis heute nachwirkenden Behauptung vom Tod des Epos. Diese gilt es allerdings zu relativieren, insbesondere wenn man den Blick über den deutschen Kulturraum und dessen Differenzierung von Trivialund Hochliteratur hinauswagt, wie Charlotte Krauss und Urs Urban in ihrem Sammelband Das wiedergefundene Epos. Darin gelingt es, das Epische als ein signifikantes Phänomen des gesamteuropäischen Kulturbetriebs aufzuzeigen, das durch das ganze 20. und bis ins 21. Jahrhundert aktuell bleibt: Angefangen bei Tolkiens Herr der Ringe ${ }^{115}$ zu zeitgenössischen Autoren wie Christoph

113 Vgl. Biere: Das andere Erzählen. Zur Poetik der Novelle 18oo/19oo. S. 23 f.

114 Vgl. Brenner: Die Krise der Selbstbehauptung: Subjekt und Wirklichkeit im Roman der Aufklärung. S. 71-142 sowie Schings, Hans-Jürg: Der anthropologische Roman. Seine Entstehung und Krise im Zeitalter der Spätaufklärung. In: Bernhard, Fabian; SchmidtBiggemann, Wilhelm; Vierhaus, Rudolf (Hrsg.): Deutschlands kulturelle Entfaltung. Die Neubestimmung des Menschen (Studien zum 18. Jahrhundert). München: Kraus International Publications 1980. S. 247-276 und Grimminger, Rolf: Roman. In: Ders. (Hrsg.): Hansers Sozialgeschichte der deutschen Literatur, Bd. 3/2. München: Hanser 1980. S. $635^{-715}$.

115 Vgl. Mouton, Margerite: Lépopée tolkienienne, enjeux idéologiques et stylistiques. In: Krauss, Charlotte; Urban, Urs (Hrsg.): Das wiedergefundene Epos. Berlin: Lit 2013. S. $79-89$. 
Ransmayr ${ }^{116}$ und Jonathan Littel ${ }^{117}$, deren umfangreiche Romane die epische Tradition aktualisieren, mit der jüngsten Publikation von Raoul Schrott ${ }^{118}$ sogar eine überstrukturierte Sprache wiederaufnehmen, bis hin zu Filmen wie Der Pate und TV-Serien wie Game of Thrones, die mit ihrem großen Erfolg beweisen, wie fruchtbar das epische Narrativ in das Medium des Films eingeht. ${ }^{119}$ Gemäß Michler macht der Gattungsboom im späten 19. Jahrhundert die Attraktivität des Epischen für kanonisierte oder kanonfähige Autoren zunichte, das Epos gilt fortan als seichte Unterhaltungsliteratur der Massen.120 Infolgedessen nimmt die Epenproduktion um und nach 1900 oberflächlich betrachtet zwar rapide ab, tatsächlich schreiben aber vermehrt unbekannt gebliebene Autoren prosaische Epen, ${ }^{121}$ die von der kulturellen Elite weitgehend unbeachtet bleiben. Demnach erleidet das epische Erzählen also vor allem einen großen Prestigeverlust. Die Gattung verliert ihre Dignität, besteht aber unterschwellig sehr wohl fort und wird in der Populärkultur des 20. und 21. Jahrhunderts europaweit immer produktiver.

Es lohnt sich allerdings auch auf den spezifischen Epikdiskurs des deutschsprachigen Kulturraums einen kritischen Blick zu werfen. Hier wird der theoretische Gattungsdiskurs des frühen 20. Jahrhunderts zunächst noch durch den ausgewiesenen Hegel-Schüler Georg Lukács und seine Romantheorie als Versuch über die Formen der großen Epik geprägt. Analog zu Hegel sieht Lukács im Epos die formale Entsprechung der Antike - eine homogene, in sich geschlossene, totale Welt, die ursprüngliche, mittlerweile aber verlorene Heimat der Menschheit. Diese „transzendentale Obdachlosigkeit“122 des Menschen in der Moderne kann nur im Roman repräsentiert werden, der die Welt so brüchig und unabgeschlossen wie sie ist und den Menschen als problematisches Individuum auf der Suche nach sich selbst zeigt. Nicht

116 Vgl. Grimm-Hamen, Sylvie: Postmoderne des Epischen im österreichischen Gegenwartsroman. In: Ebd. S. 109-130.

117 Vgl. Goyet, Florence: Über die Bedingungen der Möglichkeit eines ,Neugründungsepos‘. In: Ebd. S. 31-54.

118 Schrott, Raoul: Erste Erde. Epos. München: Hanser 2016.

119 Vgl. Boni, Marta: Cinéma italien contemporain et discours épique(s) In: Krauss; Urban (Hrsg.): Das wiedergefundene Epos. S. 155-174 sowie Urban, Urs: Die Renaissance des Epic-Films. In: Ebd. S. 175-195; Malatrait, Solveig Kristina: L'épopée à l' encre de lumière. In: Ebd. S. 197-208; Schneid, Bernd: Die Sopranos, Lost und die Rückkehr des Epos. Erzähltheoretische Konzepte zu Epizität und Psychobiographie (= Film - Medium - Diskurs, Bd. 42). Würzburg: Königshausen \& Neumann 2012.

120 Michler: Möglichkeiten einer literarischen Gattungspoetik nach Bourdieu. Mit einer Skizze zur ,modernen Versepik‘. S. 189-206, hier S. 204.

121 Ebd. S. 203.

122 Lukács, Georg: Die Theorie des Romans (1920). Bielefeld: Aisthesis 2009. S. 23. 
zufällig erscheint Lukács' Bestätigung der These vom Tod des Epos erstmals 1916: Auf dem Höhepunkt des Ersten Weltkriegs, als die Industrialisierung des Krieges und die skrupellose Verheizung von Soldatenleben den Zeitgenossen drastisch vor Augen geführt werden und die alte, heile Welt der Antike und des Epos endgültig zerbrochen scheint.

Die ins Bewusstsein getretene Historizität literarischer Formen versucht die moderne Gattungspoetologie noch bis in die Zwischenkriegszeit mit dem an Goethe anschließenden normativen Gattungssystem zu vermitteln und bemüht sich doch gleichzeitig um eine Neubegründung der Literaturwissenschaft in Absetzung zu den empiristischen Naturwissenschaften. ${ }^{123}$ In diesem Spannungsfeld zwischen Traditionsanschluss und Innovation nimmt nun die von Walter Benjamin, Robert Musil und Alfred Döblin betriebene, theoretische und literarische Restitution des Epos eine zentrale Stellung ein. Im ErzählerAufsatz von 1937 beginnt Benjamin mit dem Postulat, dass der Erzähler „in seiner lebendigen Wirksamkeit keineswegs durchaus gegenwärtig" sei, vielmehr sei er „etwas bereits Entferntes und weiter noch sich Entfernendes“, weshalb es „mit der Kunst des Erzählens zu Ende geht“.124 Die Gründe für das Verschwinden des Erzählens aus der gegenwärtigen Kultur sieht Benjamin ${ }^{125}$ zum einen in der kriegsbedingten Erfahrungsarmut des modernen Menschen, genauer in der Unmitteilbarkeit dieser Erfahrungen. Damit führt er das Erzählen auf seine mündliche Medialität zurück - in der Kritik zu Döblins Berlin Alexanderplatz schreibt er explizit: „Das mündlich Tradierbare ist das Gut der Epik“126 - und stellt gleichzeitig den Verlust von Oralität als Ursache für einen Umbruch im Literatursystem dar. ${ }^{127}$ Bereits Döblin konstatiert

123 Zur Dominanz von empiristischer Naturwissenschaft und Positivismus, die Literaturwissenschaft in Erklärungs- und Berichtigungsnotstand bringen, vgl. Oschmann, Dirk: Gestalt und Naturgeschichte. Benjamins Erzähler-Aufsatz im Horizont der zeitgenössischen Gattungspoetologie. In: Kaiser; Macher (Hrsg.): Schönheit, welche nach Wahrheit dürstet. Beiträge zur Deutschen Literatur von der Aufklärung bis zur Gegenwart. S. 299-318.

124 Benjamin, Walter: Der Erzähler. Betrachtungen zum Werk Nikolai Lesskows. In: Ders.: Gesammelte Schriften, hrsg. v. Hermann Schweppenhäuser und Rolf Tiedemann, Bd. II. Frankfurt a. M.: Suhrkamp 1977. S. 438-465, hier S. 438 f.

125 Benjamin nennt zahlreiche Gründe, hier werden diejenigen wiedergegeben, die für die vorliegende Fragestellung interessant sind, es wird daher kein Anspruch auf Vollständigkeit erhoben.

126 Benjamin, Walter: Krisis des Romans. Zu Döblins Berlin Alexanderplatz. In: Ders.: Gesammelte Schriften, hrsg. v. Rolf Tiedemann und Hermann Schweppenhäuser, Bd. III. Frankfurt a. M.: Suhrkamp 1977. S. 230-236, hier S. 213.

127 Lubkoll bezieht diese Überlegungen Benjamins auf eine kulturgeschichtliche und funktionale Betrachtung der Novelle und sieht darin den Ablöseprozess von einer mündlichen Erzählkultur hin zur schriftlich-literarischen Narration beschrieben, vgl. Lubkoll, 
in Bau des epischen Werks: „Das Buch ist der Tod der wirklichen Sprachen. Dem Epiker, der nur schreibt, entgehen die wichtigsten formbildenden Kräfte der Sprache. ${ }^{128}$ Zum anderen macht Benjamin das Aufkommen des Romans zu Beginn der Neuzeit verantwortlich für das Verschwinden des epischen Erzählens. ${ }^{129}$ Während das epische Erzählen im Kern darauf abzielt, Erfahrungen zu vermitteln - zwischen den Einzelnen aber auch zwischen dem Einzelnen und dem Kollektiv - ist „[d]ie Geburtskammer des Romans [...] das Individuum in seiner Einsamkeit, das sich über seine wichtigsten Anliegen nicht mehr exemplarisch auszusprechen vermag, selbst unberaten ist und keinen Rat geben kann. Einen Roman schreiben heißt, in der Darstellung des menschlichen Lebens das Inkommensurable auf die Spitze treiben“. 130

Für die Akteure des frühen 2o. Jahrhunderts hat der Roman die Autorität, die ihm im Laufe des 18. Jahrhunderts zuwächst und noch von Lukács explizit zugesprochen wird - nämlich die realitäts- und zeitgetreue Darstellung des modernen Menschen - gerade verloren. Der Roman nähert sich durch seinen Rückzug auf die erzählerische Vermittlung von persönlicher und individueller Innerlichkeit im Verlauf der Moderne immer stärker dem Lyrischen an. Dadurch ist er allerdings immer weniger dazu im Stande, den von Benjamin und seinen Zeitgenossen an das Erzählen gestellten Vermittlungsforderung nachzukommen. Für diese Generation von modernen Autoren machen der disparate Zustand der Gegenwart, die herrschende Isolation des Individuums und das daraus entstehende kulturelle Vakuum im Gegensatz zu Hegel nun aber gerade ein Narrativ notwendig, dass über die Darstellung von subjektiven Einzelschicksalen hinausgeht. Für sie besteht die signifikante Leistung des Epischen denn auch nicht darin, massentaugliche Unterhaltung durch Thematisierung und Ausstellung von Privatem zu sein, sondern vielmehr darin, das Individuum als Teil eines großen Ganzen darzustellen. Sie fordern also gerade wegen der Kontingenz- und Pluralitätserfahrung ein alternatives episches Erzählen zurück, das Kontinuität und Verbindlichkeit vermittelt, denn der Roman kann diese Zuständigkeit nicht erfüllen. ${ }^{131}$

Christine: Fingierte Mündlichkeit - inszenierte Interaktion. Die Novelle als Erzählmodell. In: Zeitschrift für Germanistische Linguistik 3 (2008). S. 381-402, hier S. 387 f.

128 Zitiert nach Benjamin: Krisis des Romans. Zu Döblins Berlin Alexanderplatz. S. 230-236, hier S. 213.

129 Vgl. Benjamin: Der Erzähler. Betrachtungen zum Werk Nikolai Lesskows. S. 438-465, hier S. 442.

130 Ebd. S. 443.

131 Vgl. Schneider: Erzählen im multiplen Zeitenraum. ,Restitution des Epischen‘ in der Moderne (Döblin, Benjamin, Musil). S. 215-231. 
Im Kern dieses zurückgeforderten Epischen steht die Revitalisierung der mündlichen Tradition: Nicht zuletzt unterscheidet den Roman von den anderen epischen Gattungen, dass er im Gegensatz zu Märchen, Sagen und Legenden nicht auf eine traditionelle Verwurzelung in der Sphäre von Oralität und Auralität zurückgreifen kann. Im Gegenteil steht der Roman dezidiert für eine introvertierte, schnelllebige Schriftlichkeits- und Lesekultur, wie sie erst im Zuge einer breiten Alphabetisierung der Bevölkerung und erleichterten Reproduzierbarkeit von Texten entstehen konnte. Insofern hat auch die Presse des bürgerlichen Zeitalters, die darauf ausgerichtet ist, überprüfbare, aktuelle Informationen - sprich Neuigkeiten - zu verbreiten, Anteil am Verschwinden des Epischen. Das Kriterium der Plausibilität konkurrenziert die Erfahrung als Grundlage des Erzählens. ${ }^{132}$ Ein kontemplativer Zustand der Langeweile, wie er gemäß Benjamin für das epische Erzählen ausschlaggebend ist, wird unter diesen Bedingungen kaum noch erreicht: „Die Langeweile ist der Traumvogel, der das Ei der Erfahrung ausbrütet. Das Rascheln im Blätterwalde vertreibt ihn. Seine Nester - die Tätigkeiten, die sich innig der Langeweile verbinden - sind

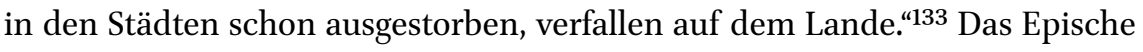
ist demnach entscheidend auf Zeit angewiesen - etwas, was der Gegenwart allerdings gerade schmerzlich abhandengekommen ist: „Die Zeit ist vorbei, in der es auf Zeit nicht ankam. Der heutige Mensch arbeitet nicht mehr an dem, was sich nicht abkürzen lässt. ${ }^{\text {134 }}$ Benjamin beschreibt diese zeitintensive epische Erzählweise als „,handwerkliche Form der Mitteilung“, an der „die Spur des Erzählenden wie die Spur der Töpferhand an der Tonschale“ haftet, das gleichwohl das "geduldige Verfahren der Natur" nachahmt und dadurch das „kostbare Werk einer langen Kette einander ähnlicher Ursachen“ ist. ${ }^{135}$ Damit setzt er das Epische auch durch eine soziokulturelle Implikation als sinnliches, kulturtechnisches ${ }^{136}$ Erzählen vom Roman und dessen Verankerung im modernen Bürgertum ab. „Das Dasein ist im Sinne der Epik ein Meer“, heißt es dazu am Eingang zum Aufsatz über Döblins Berlin Alexanderplatz. Und weiter:

132 Vgl. Benjamin: Der Erzähler. Betrachtungen zum Werk Nikolai Lesskows. S. 438-465, hier S. 444 .

133 Ebd. S. 446.

134 Ebd. S. 448.

135 Ebd. S. $447 \mathrm{f}$.

136 Vgl. Oschmann: Gestalt und Naturgeschichte. Benjamins Erzähler-Aufsatz im Horizont der zeitgenössischen Gattungspoetologie. S. 299-318, hier S. 317 . 
Es gibt nichts Epischeres als das Meer. Man kann sich natürlich zum Meer sehr verschieden verhalten. Zum Beispiel an den Strand legen, der Brandung zuhören und die Muscheln, die sie anspült, sammeln. Das tut der Epiker. Man kann das Meer auch befahren. $\mathrm{Zu}$ vielen Zwecken und zwecklos. Man kann eine Meerfahrt machen und dann dort draußen, ringsum kein Landstrich, Meer und Himmel, kreuzen. Das tut der Romancier. Er ist der wirklich Einsame, Stumme. Der epische Mensch ruht nur aus. Im Epos ruht das Volk nach dem Tagwerk; lauscht, träumt und sammelt. Der Romancier hat sich abgeschieden vom Volk und von dem, was es treibt. ${ }^{137}$

Es ist also die Aufgabe des Epikers, anders als die des Romanciers, die isolierten und vereinzelten Elemente zu sammeln, nach und nach zu einem Ganzen zu fügen und so dem modernen Individuum die Erfahrung eines homogenen, integren Sinn- und Lebenszusammenhangs zu ermöglichen, sei es auch nur ein fiktiver. Benjamin ist allerdings weit davon entfernt, die Widersprüchlichkeit zwischen Epos und Moderne schlichtweg aufzuheben. Vielmehr deutet er das bei Hegel als untrügerisches Dekadenzmerkmal dargestellte Verschwinden des Epos um, zu einer „Begleiterscheinung säkularer geschichtlicher Produktivkräfte, die die Erzählung ganz allmählich aus dem Bereich der lebendigen Sprache entrückt hat und zugleich eine neue Schönheit in dem Entschwinden fühlbar macht“.138 Es manifestiert sich zu diesem Zeitpunkt der Eposdebatte also trotz des Bewusstseins für Vereinzelung und Isolation ein deutlicher Wunsch nach Erzählbarkeit, nach Wiedereinordnung in ein kollektives, verbindliches und stabiles Weltgefüge. Damit wird das Verschwinden des Epos erstmals als dessen produktiver Antrieb sichtbar gemacht: Die Entwicklung der Gegenwart bedroht das Phänomen des Erzählens, im Moment seines Verschwindens wird es aber gerade so vergegenwärtigt, dass daran zugleich eine eigene Positionierung in Geschichte und Geschichtsphilosophie ablesbar wird. ${ }^{139}$

Die Diskussion um das Epische wird dann auch im Umfeld der zweiten Schicksalszäsur des 20. Jahrhunderts erneut virulent: 1941 schreibt Michail M. Bachtin die literaturhistorische Abhandlung Epos und Roman und Theodor W. Adorno veröffentlicht 1943 seinen Aufsatz Über epische Naivität, worin er auf die Restitution des Epischen bei Goethe und Stifter verweist. Schließlich aberkonstatieren beideim Sinne Hegels die Unmöglichkeit des Epos in der Gegenwart bzw. dessen Ablösung durch den Roman. Die ideologische

\footnotetext{
137 Benjamin: Krisis des Romans. Zu Döblins Berlin Alexanderplatz. S. 230-236, hier S. 213.

138 Ders.: Der Erzähler. Betrachtungen zum Werk Nikolai Lesskows. S. 438-465.

139 Vgl. Oschmann: Gestalt und Naturgeschichte. Benjamins Erzähler-Aufsatz im Horizont der zeitgenössischen Gattungspoetologie. S. 299-318, hier S. 302.
} 
Beschlagnahmung der Weimarer Klassik überhaupt und besonders Goethes Hermann und Dorothea sowie die unheilvolle Karriere des Totalitätsbegriffs im Nationalsozialismus leiten das abrupte Ende des deutschen Interesses am Epos nach 1945 ein, und zwar sowohl vonseiten der hochliterarischen Produktion wie auch der Philologie. Es gilt hier fortan als Ausdruck eines fundamentalen sowie aggressiven Konservatismus und Nationalismus. ${ }^{140}$

Diese nur skizzenhaften Ausführungen offenbaren zwei zentrale Anknüpfungspunkte für die leitenden Thesen der vorliegenden Arbeit: Erstens die einhellige und gut erforschte Differenzierung und Hierarchisierung von Roman und Epos in der Moderne sowie ein gleichzeitiges Festhalten am Begriff des Epischen trotz des proklamierten Gattungstodes, wodurch die im 19. und 20. Jahrhundert etablierte Forschungsmeinung von der erwiesenen Unzeitmäßigkeit des Epos kontrastiert wird. Werfen wir nun erneut einen Blick auf Hegels konstruierte Diagnose vom Tod des Epos, bewahrheitet diese sich nicht, mehr noch trifft sie nicht einmal zum Zeitpunkt ihrer Formulierung wirklich zu: Hegels Zeitgenossen debattieren angeregt über die gerade im Zeichen der Nationalphilologie rekonstruierten Epen der mittelalterlichen Vergangenheit und bringen gleichzeitig selbst Texte hervor, die explizit im Zeichen des Epischen geschrieben oder von der Leserschaft als episch aufgefasst werden. ${ }^{141}$ Es lässt sich weder die Unterstellung vom Tod des Epos aufgrund der subjektiv-kontingenten Verfasstheit der Moderne, noch die Behauptung eines idealtypischen, totalen Ur-Epos in der Antike belegen: Nicht nur persistiert das Epos in der Moderne offensichtlich in hybriden und fragmentierten Formen, sondern es war bereits in der Antike nicht die homogene, in sich geschlossene Kunstform, als die es lange angesehen worden war. Das legen zum einen die Schwierigkeiten bei der Definition des Epos eines Aristoteles nahe und zum anderen die hier noch ausführlicher zu behandelnden Erkenntnisse des Altphilologen Wolf. ${ }^{142}$ Aufschlussreich sind Hegels Thesen und vor allem auch deren ungeprüfte Fortschreibung insofern als daran aus heutiger Sicht die problematische Verfasstheit jener bürgerlichen Gemeinschaft ablesbar wird, die sich mit einer derartigen Geschichts- und Literaturkonstruktion zu versichern versucht, dass sie eine historisch gewachsene, stabile kollektive Identität hat und dass sich tradierte Narrationsmuster in gesellschaftliche

140 Vgl. Elsaghe: Säbel und Schere. Goethes Revolutionierung des Epos und die Rezeptionskarriere von Hermann und Dorothea. S. 121-136 und Morgan, Peter: Aufklärung, Revolution und Nationalgefühl. Der Topos des Jakobiners und die Frage deutscher Identität in Goethes Hermann und Dorothea In: Zeitschrift für Germanistik NF 1 (1991). S. 533-543.

141 Vgl. Einleitung in Krauss; Urban (Hrsg.): Das wiedergefundene Epos. S. 8 f.

142 Vgl. S. 46 ff. in diesem Buch. 
Kohäsionskräfte übersetzen lassen. In der Rückwendung auf das Epos findet nicht nur die Ablehnung, sondern tatsächlich eine wenn auch aporetische Selbstvergewisserung der Moderne statt: Just in dem Moment, in dem das Subjekt selbstbewusst aus den alten Ordnungsgefügen heraustritt, wird das Epos zum Spiegel dieser doch äußerst problematischen Emanzipation und verspricht gleichzeitig trotzdem die Möglichkeit, einen glücklichen, integrativen Sinn- und Lebenszusammenhang zu vermitteln. Es wird hier deutlich, dass die Funktions- und Merkmalszuschreibungen des Epos schon seit jeher stark von Interessen vorgegeben werden, die außerhalb des literarischen Feldes angesiedelt sind. Das Eposkonzept der Moderne macht gerade das eigene Ableben, oder zumindest die Rede davon, zum produktiven Antrieb. Eva Geulen bemerkt in diesem Zusammenhang, dass jede Rede vom Ende der Kunst - und damit auch die Behauptung vom Ende des Epos - ein gespaltenes Verhältnis zu ihrem Gegenstand hat. Sie ist entweder verfrüht oder zu spät, sie widerspricht sich jedenfalls stets selbst, denn solange noch bzw. wieder darüber geredet wird, kann das Epos gar nicht tot sein. ${ }^{143}$ Die Behauptung vom Tod des Epos wurde, gleich wie die Rede vom Ende der Kunst, zu einem Topos der Moderne, zum literaturtheoretischen Gemeinplatz. Bei Nietzsche, Lukács und Bachtin wird Hegels Dekadenzdiagnose einer kunst- und eposlosen Gegenwart unwidersprochen übernommen. Wie es im Folgenden zu zeigen gilt, setzt die Rhetorik vom Tod des Epos aber bereits vor derjenigen vom Ende der Kunst ein, nämlich in den 179oer Jahren, und fungiert quasi als deren Wegbereiter. Seit die Rede vom Ende des Epos eingesetzt hat, erlebte das Eposkonzept derart zahlreiche Aktualisierungen, dass hier in Anlehnung an Eva Geulen die Behauptung aufgestellt wird, dass das, was das Epos alles war, sein sollte und vielleicht noch werden wird, ohne die Rhetorik von dessen Ende gar nicht vorstellbar wäre. ${ }^{144}$ Diese regt stets von Neuem dazu an, das Epos wieder zu beleben, nach ihm zu suchen, es neu zu erfinden und es bisweilen aber gerade auch produktiv zu verfehlen.

Zweitens scheint es einen spezifischen Zusammenhang zu geben zwischen der historischen Erschütterung des gesellschaftlich-kulturellen Selbstverständnisses, einer nur noch im permanenten Umbruch begriffenen Gegenwart sowie den daraus neu hervorgehenden Bedürfnissen nach Stabilität und Kontinuität zum einen und der ungebrochenen Virulenz des epischen Narrativs zum anderen. Denn der Begriff des Epischen zieht sich trotz - oder gerade wegen - der vielbeschworenen Inkompatibilität von Epos und Moderne

\footnotetext{
143 Vgl. Geulen, Eva: Das Ende der Kunst. Lesarten eines Gerüchts nach Hegel. Frankfurt a. M.: Suhrkamp 2002. S. 9 .

144 Vgl. ebd. S. 10.
} 
wie ein roter Faden durch die neuere Kulturgeschichte. Inwiefern episches Erzählen von Interesse ist für ein Zeitalter, dessen vorherrschende Symptomatik die Krise ${ }^{145}$ ist, hat die jüngere Forschung für das 19. und 20. Jahrhundert bereits einleuchtend herausgearbeitet. ${ }^{146}$ Wie Dirk Oschmann an Benjamins Erzähler-Aufsatz aufzeigt, beruht dessen Bemühung um das Epische dezidiert auf dem Bewusstwerden einer umfassenden Krise, die sich auch in der Literaturgeschichte, der Bildung, der Intelligenz und der Kunst überhaupt manifestiert. ${ }^{147}$ Im modernen Epikdiskurs werden die Ausdifferenzierungsund Dynamisierungsprozesse des Gattungssystems verhandelt und darin spiegeln sich wiederum die zentralen Probleme der kulturell-gesellschaftlichen Auflösungstendenzen: die ab Mitte des 18. Jahrhunderts einsetzende Erschütterung der sozialen Ordnung sowie der Geltungsverlust der Kunst für die Kulturtradition. Das Epische erscheint unter diesem Gesichtspunkt in Abgrenzung zum Roman als ausgemachtes Krisenphänomen - zum einen steht paradoxerweise seine Restitution in konstitutivem Zusammenhang mit seiner Verabschiedung und zum anderen ist es darauf angelegt, just die Krise, die zu seiner Rückforderung geführt hat, narrativ zu lösen. Dabei wird klar, dass das Epos für die Verhandlung und Vermittlung politischer, sozialer sowie kultureller Ideale eine wichtige Rolle spielt und immer dann aktualisiert wird, wenn diese brüchig zu werden drohen. Dem epischen Erzählen ist insofern das

145 Vgl. dazu Karl Jaspers, ein Zeitgenosse Benjamins: „Was in Jahrtausenden die Welt des Menschen war, scheint heute zusammenzubrechen. [...] Der Mensch scheint in das aufzugehen, was nur Mittel, nicht Zweck, geschweige denn Sinn sein sollte. [...] Alles ist fraglich geworden, alles sieht sich in seiner Substanz bedroht. Wie sonst die Wendung geläufig war, wir lebten in einer Übergangszeit, so ist jetzt in jeder Zeitung von Krise die Rede. Man fragt nach dem tieferen Grund und findet die Staatskrise; wenn die Weise des Regierens zu keiner entschiedenen Willensbildung des Ganzen führt und die Gesinnung der Zustimmung schwankt, schwankt alles." Jaspers, Karl: Die geistige Situation der Zeit, 7. Abdruck der im Sommer 1932 bearbeiteten 5. Auflage. Berlin: de Gruyter 1971. S. 72 ff.

146 Der bereits erwähnte Sammelband Das wiedergefundene Epos von Krauss und Urban legt den Fokus auf den Höhepunkt einer vielgestaltigen Epos-Produktion in der zweiten Hälfte des 19. Jahrhunderts, fragt dezidiert nach der Bedeutung politischer Umbrüche und der Gewalterfahrungen des 20. Jahrhunderts für die Persistenz des Epischen bzw. für seine Wiederkehr in neuen Gewändern und spürt in allen Beiträgen ein historisch verfasstes, politisches Interesse als Antrieb für die epische Produktion auf. Und auch Michler attestiert dem Epos eine schon immer eingespeicherte soziale Energie, die sich transformieren und deren Kraft sich reaktualisieren lässt, vgl. Michler: Möglichkeiten einer literarischen Gattungspoetik nach Bourdieu. Mit einer Skizze zur ,modernen Versepik؛ S. 189-206, hier S. 198.

147 Vgl. Oschmann: Gestalt und Naturgeschichte. Benjamins Erzähler-Aufsatz im Horizont der zeitgenössischen Gattungspoetologie. S. 299-318, hier S. 308. 
Potenzial zur Bewältigung von kollektiver und systematischer Verunsicherung eingeschrieben, welches dem Roman nicht zugestanden wird. ${ }^{148}$

Für die kulturelle Moderne ${ }^{149}$ lassen sich innerhalb des epischen Gattungsdiskurses also zwei Haupttraditionslinien ausmachen, an denen sich auch die Auseinandersetzungen zwischen Poesie und Prosa, Epos und Roman, populärer und intellektueller Kunst, sowie geschichtsphilosophischer und kulturanthropologischer Literaturtheorie manifestieren. Die eine und zugleich dominante führt über Herders Begriff der Volkspoesie in die Romantik, zu Hegel und den ihm wenn auch nicht in allen Aspekten aber doch im Gesamturteil folgenden Epospoetiken Vischers, Lukács' und Bachtins. Während die andere, nennen wir sie vorläufig die klassizistische, über Wolf zu Goethe, Schiller und Humboldt verläuft. Sie führt zwar auch zu Hegel, aber - so die These dieser Arbeit - von hier an unterschwellig über ihn hinaus bis zu Walter Benjamin und kann als alternative Traditionslinie eines Gegenkanons der Moderne aufgezeigt werden. ${ }^{150}$

Der Eposdiskurs der Epochenschwelle, an dem sich Vertreter sowohl der klassizistischen wie auch der romantischen Geisteshaltung gleichermaßen beteiligen und der die umfangreichste, vielstimmigste und expliziteste Auseinandersetzung mit dem epischen Erzählen seit der Antike darstellt, wird in dieser Arbeit als entscheidender Moment der Eposbestimmung bzw. -erneuerung verstanden, in dem die Zurückweisung des Epos wie auch dessen Vereinnahmungen durch die anbrechende Moderne gleichzeitig einsetzen. Wieso ist aber ausgerechnet das Epos so zentral für den klassizistischromantischen Gattungsdiskurs? In diesem Sinn gilt es im Weiteren nach dem Ursprung und den Bedingungen eines spezifisch modernen epischen Erzählens zu fragen, dessen Verortung in der Sattelzeit um 1800 nicht zuletzt durch die neusten Forschungsergebnisse legitimiert wird. Denn obwohl selbst Christians nicht über die Feststellung hinauskommt, dass es sich bei Goethes Erfolgsschlager Hermann und Dorothea um ein „irritierendes Moment der Literaturgeschichte“ ${ }^{\prime 51}$ handle, kommt bezeichnenderweise

148 Vgl. Krauss; Mohnike (Hrsg.): Auf der Suche nach dem verlorenen Epos. Ein populäres Genre des 19. Jahrhunderts. S. 5-13 (Vorwort).

149 Kulturelle Moderne wird hier in Anschluss an Heinz Brüggemann als „longue durée“ seit der 2. Hälfte des 18. Jahrhunderts/Aufklärung verstanden, vgl. dazu Brüggemann: Modernität im Widerstreit. Zwischen Pluralismus und Homogenität. Eine Theorie-, Kultur- und Literaturgeschichte (18.-20. Jahrhundert). S. 17-29 (Einleitung).

150 Vgl. Schneider: Erzählen im multiplen Zeitenraum. ,Restitution des Epischen' in der Moderne (Döblin, Benjamin, Musil). S. 215-231 und dies.: Entschleunigung. Episches Erzählen im Moderneprozess. S. 247-264.

$15^{1}$ Christians: Der Traum vom Epos. Romankritik und politische Poetik in Deutschland (1750-2000). S. 11 . 
keine der erwähnten Bemühungen um die Persistenz des Epos in der Moderne ohne Rekurs auf die Gattungsentwicklung und -reflexion am Ende des 18. Jahrhunderts aus. Welche Dimensionen des Epischen werden bereits zu diesem Zeitpunkt virulent, wie werden sie bestimmt und produziert? Welche Forderungen und Funktionen werden als gattungsbestimmend an sie herangetragen? In welchem Kontext mit zeitgenössischen Diskursen stehen diese Forderungen? Welche Wechselwirkungen zwischen historischer Erfahrung, politischer Ideologie und literarischer Reflexion werden im epischen Gattungsdiskurs und durch die Epenproduktion aktualisiert? Diesen Leitfragen soll im Folgenden nachgegangen werden. 